OPEN ACCESS

Edited by: Chris Greening,

Monash University, Australia

Reviewed by:

Armen Trchounian,

Yerevan State University, Armenia

Kyle Costa,

University of Minnesota Twin Cities,

United States

*Correspondence:

Volker Müller

vmueller@bio.uni-frankfurt.de

Specialty section:

This article was submitted to Microbial Physiology and Metabolism, a section of the journal

Frontiers in Microbiology

Received: 30 August 2018 Accepted: 13 November 2018 Published: 04 December 2018

Citation:

Schuchmann K, Chowdhury NP and Müller V (2018) Complex Multimeric [FeFe] Hydrogenases: Biochemistry, Physiology and New

Opportunities for the Hydrogen Economy. Front. Microbiol. 9:2911.

doi: 10.3389/fmicb.2018.02911

\section{Complex Multimeric [FeFe] Hydrogenases: Biochemistry, Physiology and New Opportunities for the Hydrogen Economy}

\author{
Kai Schuchmann, Nilanjan Pal Chowdhury and Volker Müller* \\ Molecular Microbiology and Bioenergetics, Institute of Molecular Biosciences, Johann Wolfgang Goethe University,
} Frankfurt am Main, Germany

Hydrogenases are key enzymes of the energy metabolism of many microorganisms. Especially in anoxic habitats where molecular hydrogen $\left(\mathrm{H}_{2}\right)$ is an important intermediate, these enzymes are used to expel excess reducing power by reducing protons or they are used for the oxidation of $\mathrm{H}_{2}$ as energy and electron source. Despite the fact that hydrogenases catalyze the simplest chemical reaction of reducing two protons with two electrons it turned out that they are often parts of multimeric enzyme complexes catalyzing complex chemical reactions with a multitude of functions in the metabolism. Recent findings revealed multimeric hydrogenases with so far unknown functions particularly in bacteria from the class Clostridia. The discovery of [FeFe] hydrogenases coupled to electron bifurcating subunits solved the enigma of how the otherwise highly endergonic reduction of the electron carrier ferredoxin can be carried out and how $\mathrm{H}_{2}$ production from $\mathrm{NADH}$ is possible. Complexes of [FeFe] hydrogenases with formate dehydrogenases revealed a novel enzymatic coupling of the two electron carriers $\mathrm{H}_{2}$ and formate. These novel hydrogenase enzyme complex could also contribute to biotechnological $\mathrm{H}_{2}$ production and $\mathrm{H}_{2}$ storage, both processes essential for an envisaged economy based on $\mathrm{H}_{2}$ as energy carrier.

Keywords: hydrogenase, formate dehydrogenase, $\mathrm{CO}_{2}$ reduction, electron bifurcation, hydrogen production, acetogenesis, clostridia, hydrogen storage

\section{INTRODUCTION}

Molecular hydrogen $\left(\mathrm{H}_{2}\right)$ is only present in trace concentrations (550 parts per billion) in the Earth's lower atmosphere (Novelli et al., 1999). Nevertheless, it plays an essential part in the biogeochemical cycles of other elements such as carbon and is a major constituent of the microbial metabolism. For example, $\mathrm{H}_{2}$ is an important electron donor for methane formation in anoxic environments (Schink, 1997; Thauer et al., 2008). Here, too, steady state concentrations are very low $\left(\mathrm{pH}_{2}<10 \mathrm{~Pa}\right.$ ) but the turnover of $\mathrm{H}_{2}$ is very high ( 150 million tons of $\mathrm{H}_{2}$ of biological origin are estimated to be produced in anoxic ecosystem annually to fuel methanogenesis) (Thauer et al., 2008, 2010). In anoxic ecosystems, the major role of $\mathrm{H}_{2}$ is electron transfer between the different participants of the food chain, e.g., transfer of electrons generated by primary fermenters to methanogens (Stams and Plugge, 2009; Schink et al., 2017). To produce or consume $\mathrm{H}_{2}$ nature has evolved complex metalloenzymes, hydrogenases, which catalyze one of the simplest chemical reaction, reversible 
oxidation of $\mathrm{H}_{2}$ into two protons and two electrons:

$$
H_{2} \rightleftharpoons 2 H^{+}+2 e^{-}
$$

Hydrogenases are widespread in nature and can be found in all domains of life. Based on their phylogeny, they can be classified into three distinct classes that are named by the metal ions contained in their active sites as $[\mathrm{NiFe}]-,[\mathrm{FeFe}]-$, and [Fe] hydrogenases (Vignais et al., 2001; Vignais and Colbeau, 2004). [NiFe] hydrogenases have been found in bacteria and archaea, $[\mathrm{FeFe}]$ hydrogenases in bacteria and some eukaryotes, and $[\mathrm{Fe}]$ hydrogenases only in archaea (Vignais and Billoud, 2007). Even though [NiFe]- and [FeFe] hydrogenases have evolved independently, the complex metal centers responsible for catalysis share many features. The metal ions are ligated by inorganic $\mathrm{CO}$ and $\mathrm{CN}^{-}$ligands and are bridged by sulfur atoms. $\mathrm{H}_{2}$ can reach the active sites that are buried within the enzymes by a hydrophobic gas channel and the electrons that result from $\mathrm{H}_{2}$ oxidation are in both enzyme classes transferred to an [4Fe4S] cluster adjacent to the metal center (Happe et al., 1997; Pierik et al., 1998; Fontecilla-Camps and Ragsdale, 1999). The third class of hydrogenases, the $[\mathrm{Fe}]$ hydrogenases which are only found in methanogenic archaea differ not only by their architecture of the active site, but also by the catalyzed reaction that does not result in the release of electrons to an iron-sulfur cluster, but the direct transfer to the cosubstrate methenyltetrahydromethanopterin (Shima and Thauer, 2007; Shima et al., 2008). In this review, we will mainly focus on hydrogenases of the [FeFe] class. Enzymes from this class are widespread in anaerobic prokaryotes and play important roles in the energy and carbon metabolism in anoxic ecosystems. Crystal structures have been reported for three enzymes, namely from Clostridium pasteurianum (Peters et al., 1998), Desulfovibrio desulfuricans (Nicolet et al., 1999) and the eukaryotic algae Chlamydomonas reinhardtii (Mulder et al., 2010) and show high similarity in the overall structure and the architecture of the active site. Details on the crystal structures and the reaction mechanism have been described in excellent and comprehensive reviews elsewhere and will therefore not been repeated here except for the architecture of the cofactors in the C. pasteurianum enzyme that we will discuss in the context of electron bifurcation later (Vignais and Colbeau, 2004; Thauer et al., 2010; Lubitz et al., 2014). Interestingly, despite the apparent high similarity of the "core" hydrogenase subunit responsible for $\mathrm{H}_{2}$ oxidation and production, [ $\left.\mathrm{FeFe}\right]$ hydrogenases show a remarkable diversity with respect to the auxiliary subunits that can be found in most enzymes and an even higher diversity can be predicted from genome sequence data. The auxiliary subunits follow a very modular structure and add multiple functions to the core subunit. These functions can include electron transfer to soluble electron carriers, coupling of $\mathrm{H}_{2}$ oxidation/production to other chemical reactions, coupling to energy conservation by coupling the electron transfer to the generation of a transmembrane ion potential, or utilization of the novel energetic coupling mechanism of flavin-based electron bifurcation (FBEB) to overcome energetic limitations of the electron transfer (Buckel and Thauer, 2018a,b; Müller et al., 2018). A notable diversity of multimeric $[\mathrm{FeFe}$ hydrogenases can be found especially in the strictly anaerobic Gram-positive bacteria of the class Clostridia within the phylum Firmicutes (Calusinska et al., 2010; Schmidt et al., 2010). Recent discoveries have revealed multimeric hydrogenases with remarkable and so far undescribed functions and catalytic properties, solving important questions of the metabolism and ecosystem functioning in anoxic environment. In addition, recently described multimeric hydrogenases provide interesting opportunities for biotechnological applications. $\mathrm{H}_{2}$ is a candidate energy carrier that could replace fossil fuels for storage and transportation of energy generated from renewable sources such as wind or solar power (Dunn, 2002; Brandon and Kurban, 2017). However, for an economically viable $\mathrm{H}_{2}$ economy many obstacles need to be overcome such as efficient methods for $\mathrm{H}_{2}$ production and technologies for storage and transportation of the volatile and explosive gas (Service, 2004; Preuster et al., 2017a).

Here, we review the recent findings of novel complex multimeric hydrogenases and especially their function in the microbial $\mathrm{H}_{2}$ metabolism. These include enzymes using the novel energy coupling mechanism of FBEB enabling otherwise endergonic $\mathrm{H}_{2}$ production from $\mathrm{NADH}$ or the otherwise endergonic electron transfer from $\mathrm{H}_{2}$ to the iron-sulfur protein ferredoxin. The second part will focus on the recently discovered formate dehydrogenase coupled hydrogenases enabling direct $\mathrm{CO}_{2}$ reduction with $\mathrm{H}_{2}$ or $\mathrm{H}_{2}$ evolution from formate. In addition, both hydrogenase types will be discussed in the context of their biotechnological potential for the $\mathrm{H}_{2}$ economy.

\section{$\mathrm{H}_{2}$ FUNCTIONING AS ELECTRON CARRIER IN ANOXIC ECOSYSTEMS}

$\mathrm{H}_{2}$ can be utilized by many organisms as electron donor. Recently, it has been reported that microorganisms are even capable of utilizing the low atmospheric concentrations of $\mathrm{H}_{2}$ (Greening et al., 2014a,b). Nevertheless, the most prominent functions of $\mathrm{H}_{2}$ are found in anoxic ecosystems where it is rapidly produced and consumed by microorganisms resulting in a large turnover. $\mathrm{H}_{2}$ connects different parts of the food web to allow full remineralization of organic material. When complex polymeric organic material (polysaccharides, proteins, nucleic acids, lipids) enter anoxic ecosystems it is typically first hydrolyzed by exoenzymes followed by the partial oxidation by primary fermenting microorganisms into different fermentation products such as lactate, alcohols, short chain fatty acids, acetate, formate, $\mathrm{CO}_{2}$ and $\mathrm{H}_{2}$. In the absence of suitable external electron acceptors, the latter compounds (acetate, formate, $\mathrm{CO}_{2}$ and $\mathrm{H}_{2}$ ) can be directly converted by methanogenic archaea into methane (Schink, 1997; Thauer et al., 2008). Further oxidation of the other compounds leads to an energetic problem that can only be solved by the concerted cooperation of secondary fermenting organisms with methanogens in a process call syntrophy (Schink, 2002; Sieber et al., 2012; Morris et al., 2013). Secondary fermenters oxidize their substrates typically to acetate as end product coupled to oxidation of protons to $\mathrm{H}_{2}$ to reoxidize their electron carriers. However, under standard conditions these reactions are endergonic and do not provide 
energy for the cell. During substrate oxidation, electrons are typically transferred to either ferredoxin, a small iron-sulfur cluster containing protein with a very negative redox potential $\left(\mathrm{E}^{\circ}=-400\right.$ to $\left.-500 \mathrm{mV}\right)$, or $\mathrm{NAD}^{+}$with a more positive redox potential $\left(\mathrm{E}^{\circ}\left[\mathrm{NAD}^{+} / \mathrm{NADH}\right]=-320 \mathrm{mV}\right.$ ) (Thauer et al., 1977). Proton reduction can be used to recycle these electron carriers. The redox potential of the $\mathrm{H}^{+} / \mathrm{H}_{2}$ couple is, under standard conditions, $-414 \mathrm{mV}$. Therefore, while $\mathrm{H}_{2}$ production from reduced ferredoxin is an exergonic reaction, $\mathrm{H}_{2}$ formation from $\mathrm{NADH}$ represents a strong energetic barrier for the cells since it is a highly endergonic reaction (Thauer et al., 1977). Two possible mechanisms have evolved to overcome this problem and allow $\mathrm{H}_{2}$ formation from $\mathrm{NADH}$. In the classical view, $\mathrm{H}_{2}$ oxidizing methanogens lower the $\mathrm{H}_{2}$ partial pressure to very low values (1-10 $\mathrm{Pa} \mathrm{H}_{2}$ ) resulting in a more positive redox potential of the $\mathrm{H}^{+} / \mathrm{H}_{2}$ couple (above $-300 \mathrm{mV}$ ) thus rendering $\mathrm{H}_{2}$ formation from NADH an exergonic reaction (Schink, 2002; Sieber et al., 2012; Morris et al., 2013). Recently, another mechanism has been discovered that solves the problem of NADH reoxidation with protons as acceptor within one enzyme. Complex multimeric hydrogenases are necessary to catalyze this reaction that solves the energetic problem by energetically coupling the endergonic electron transfer to a second exergonic redox reaction, a process called FBEB. As we will see later, these enzymes not only participate in the metabolism of secondary fermenting organisms but can also be found in primary fermenters, thereby increasing the energy yield that can be conserved from a given substrate, or, in the reverse, be found in acetogenic bacteria to allow ferredoxin reduction with $\mathrm{H}_{2}$ as electron donor.

\section{THE CONCEPT OF FLAVIN-BASED ELECTRON BIFURCATION}

In 2008 a new energy coupling mechanism called FBEB was first discovered in an enzyme complex of an electrontransferring flavoprotein and a butyryl-CoA dehydrogenase (Etf/Bcd) (Herrmann et al., 2008; Li et al., 2008). In FBEB, an electron pair from an electron donor such as $\mathrm{NADH}$ is split toward two different one-electron acceptors, one with a more positive redox potential and another with a much lower redox potential than that of the electron donor. It was proposed and later proven that electron transfer to a positive redox potential (exergonic reaction) sustains the movement of an electron to a more negative redox potential (endergonic reaction). In case of Etf/Bcd, the positive electron redox potential acceptor was crotonyl-CoA $\left(\mathrm{E}^{0}=-10 \mathrm{mV}\right)$ and the negative redox potential acceptor was ferredoxin $\left(\mathrm{E}^{0}=-420 \mathrm{mV}\right) . \mathrm{NADH}\left(\mathrm{E}^{0}=-320\right.$ $\mathrm{mV}$ ) is the electron donor. The complete reaction catalyzed by the protein complex is

$$
\begin{aligned}
& \text { Crotonyl }-\mathrm{CoA}+2 \mathrm{NADH}+\mathrm{Fd}_{\mathrm{ox}} \\
& \rightarrow \text { Butyryl }-\mathrm{CoA}+2 \mathrm{NAD}^{+}+\mathrm{Fd}_{\mathrm{red}}
\end{aligned}
$$

The enzyme complex contained FAD as the only cofactor that was essential for the activity (Chowdhury et al., 2014; Demmer et al., 2017). Hence, the name originated as FBEB. FBEB was drawn in analogy to the quinone-based electron bifurcation (QBEB) of the cytochrome $b_{1}$ complex of the respiratory chain, which was discovered 43 years ago by Peter Mitchell, in which the oxidation of reduced ubiquinone $\left(\mathrm{UQH}_{2}\right)$ by the high potential cytochrome $c_{1}$ by one electron allows the reduction of lowpotential cytochrome $b_{L}$ and further UQ inside the membrane (Mitchell, 1975). The process is repeated twice that allows four protons to be released outside of the cell and doubling the amount of energy conserved and electrons finally flow down to oxygen (terminal electron acceptor) to reduce oxygen to water.

\section{$\mathrm{H}_{2}$ PRODUCTION FROM NADH: ELECTRON-BIFURCATING HYDROGENASES FOR $\mathrm{H}_{2}$ EVOLUTION}

Soon after the discovery of FBEB in Clostridia, the first hydrogenase was reported that utilizes the mechanism of FBEB, however, in the physiological context in the reverse direction (named electron confurcation) (Schut and Adams, 2009). The enzyme was discovered in the hyperthermophilic and anaerobic bacterium Thermotoga maritima. The bacterium ferments one mole of glucose by the classical Embden-Meyerhof-Parnas pathway to two moles of $\mathrm{CO}_{2}$, two acetate and four moles of $\mathrm{H}_{2}$ (Schroder et al., 1994). During its metabolism, both $\mathrm{NADH}$ and reduced ferredoxin are generated, however, for decades the link to the oxidation of these electron carriers to $\mathrm{H}_{2}$ production remained obscure (Wrba et al., 1990; Blamey and Adams, 1993). The trimeric [FeFe] hydrogenase was isolated and could be assayed by coupling reduction of viologen dyes with $\mathrm{H}_{2}$. However, the enzyme did not use either reduced ferredoxin or $\mathrm{NADH}$ as sole electron donor (Verhagen et al., 1999). Though reduced clostridial ferredoxin $\left(\mathrm{E}^{0}=-420 \mathrm{mV}\right)$ alone can reduce protons to $\mathrm{H}_{2}\left(\mathrm{E}^{0}=-414 \mathrm{mV}\right), \mathrm{NADH}$ cannot. It was an enigma since the discovery of fermentative $\mathrm{H}_{2}$ production to how $\mathrm{H}_{2}$ is produced from NADH. The solution was FBEB: exergonic electron flow from reduced ferredoxin to $\mathrm{H}^{+}$that drives endergonic electron flow from $\mathrm{NADH}$ to $\mathrm{H}^{+}$, according to:

$$
\mathrm{NADH}+\mathrm{Fd}_{\text {red }}+3 \mathrm{H}^{+} \rightleftharpoons \mathrm{NAD}^{+}+\mathrm{Fd}_{\mathrm{ox}}+2 \mathrm{H}_{2}
$$

The hydrogenase of $T$. maritima is now the classic example where reduced ferredoxin drives $\mathrm{H}_{2}$ evolution from NADH. The enzyme oxidizes NADH and ferredoxin simultaneously in a 1:1 ratio to produce $\mathrm{H}_{2}$. In this case both electrons from $\mathrm{NADH}$ and reduced ferredoxin are converged to reduce protons to $\mathrm{H}_{2}$. This mode of electron converging from different sources of electron donor $\left(\mathrm{NADH}\right.$ and $\left.\mathrm{Fd}_{\text {red }}\right)$ to a single electron acceptor (protons) is now called electron confurcation. A similar lifestyle and metabolic pathway is also observed in the rumen bacterium Ruminococcus albus (Zheng et al., 2014). Similar to T. maritima, when grown in continuous culture the bacterium produces the same amounts of $\mathrm{H}_{2}$ and acetate from glucose (Figure 1A). Also, the acetogenic model bacterium Acetobacterium woodii is suggested to use a confurcating hydrogenase to evolve $\mathrm{H}_{2}$ from organic substrates (Schuchmann and Müller, 2012; Bertsch et al., 2015; Kremp et al., 2018). This mode of $\mathrm{H}_{2}$ evolution 
A

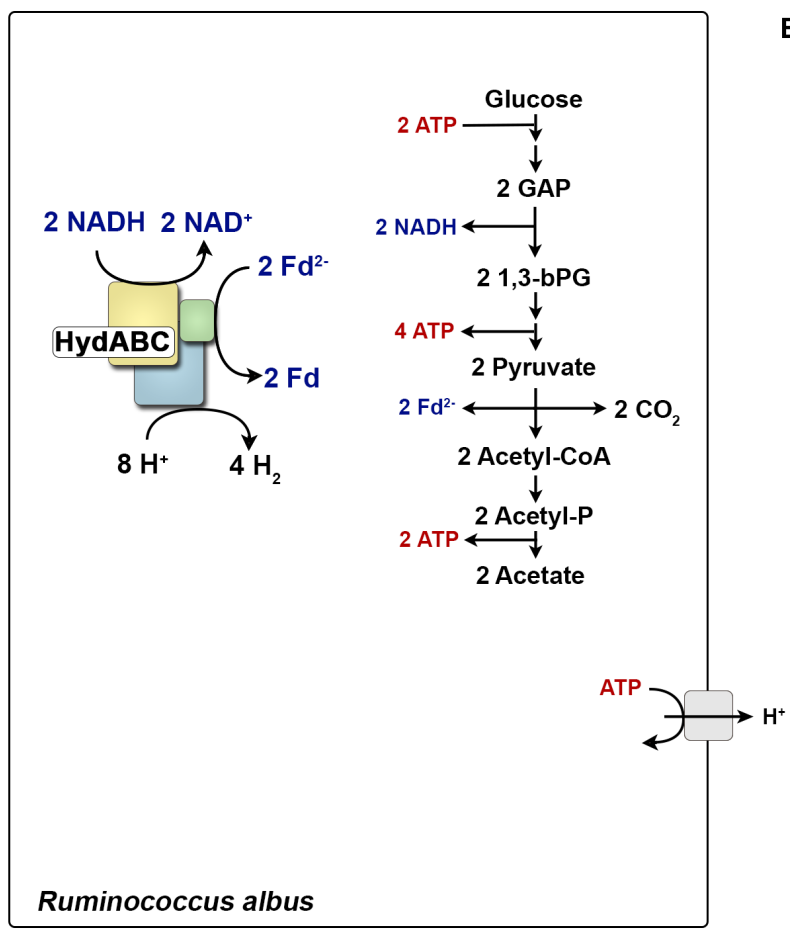

B

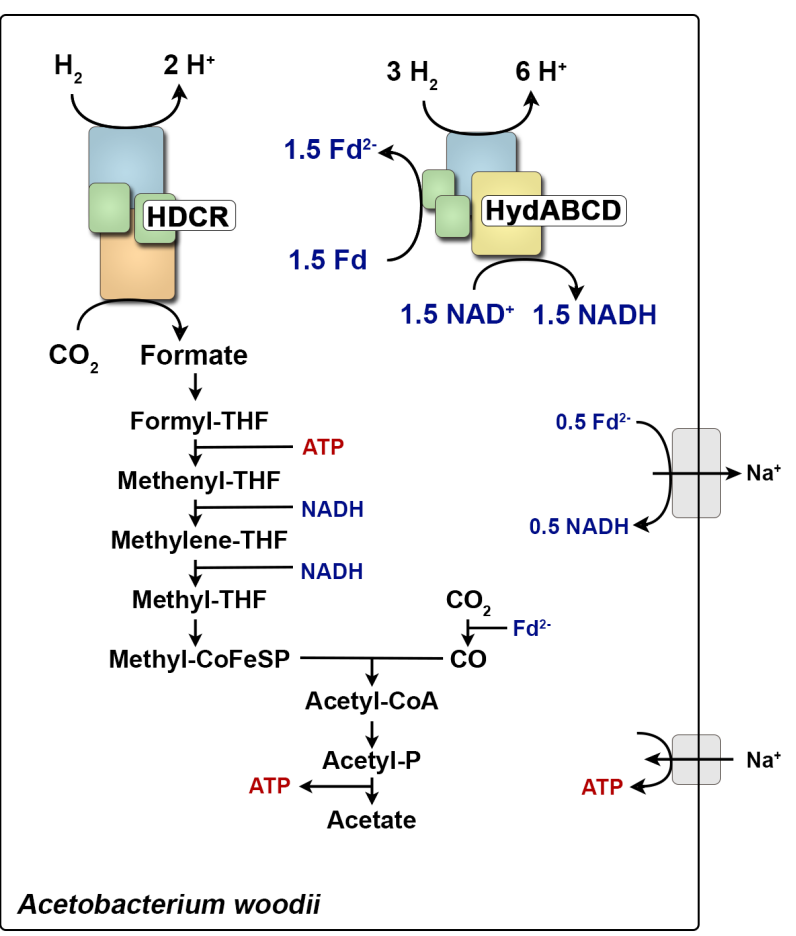

FIGURE 1 | Role of multimeric hydrogenases in the energy metabolism of Ruminococcus albus (A) and Acetobacterium woodii (B). During glucose fermentation, $R$. albus oxidizes glucose to two molecules acetate. All generated reducing equivalents are reoxidized by the electron confurcating hydrogenase HydABC. In contrast, $A$. woodii can grow with $\mathrm{H}_{2}+\mathrm{CO}_{2}$ as substrates and forms acetate as major end product. $\mathrm{HDCR}$ catalyzes the first step of the WLP from $\mathrm{CO}$ 2 to formate. All reducing equivalents are provided from $\mathrm{H}_{2}$ oxidation catalyzed by the electron bifurcating hydrogenase $\mathrm{HydABCD}$. Fd ${ }^{2-}$, reduced ferredoxin; CoA, coenzyme-A; THF, tetrahydrofolate; CoFeSP, corrinoid-iron-sulfur protein; GAP, glyceraldehyde 3-phosphate; 1,3-bPG, 1,3-bisphosphoglycerate.

by electron confurcating hydrogenases is important for energy conservation in these fermenting bacteria. ATP is synthesized by substrate level phosphorylation at the phosphoglycerate kinase and pyruvate kinase reactions and NADH is formed by NADspecific glycerinaldehyde-3-phosphate-dehydrogenase. The redox pool could for example be balanced by reducing pyruvate to lactate, where $2 \mathrm{NADH}$ will be consumed. However, this pathway will produce 2 ATP less. Rather the bacteria maintain its redox balance by producing two moles of acetyl-CoA via the pyruvateferredoxin oxidoreductase and finally releases 2 ATP catalyzed by the acetate kinase. This mode of metabolism leaves $2 \mathrm{NADH}$ and 2 reduced ferredoxin that are converted to $\mathrm{H}_{2}$ by FBEB hydrogenase. Hence, the presence of FBEB hydrogenases allows $\mathrm{NADH}$ and ferredoxin to be reoxidized with $\mathrm{H}^{+}$as electron acceptor and thus increasing the ATP yield (Müller et al., 2018).

\section{ELECTRON-BIFURCATING UPTAKE HYDROGENASES}

In the autotrophic mode of life, organisms can synthesize most of their carbon compounds from $\mathrm{CO}_{2}$ using $\mathrm{H}_{2}$ or another electron donor as reductant. One such group are the acetogenic bacteria that are capable of producing acetate from two molecules of $\mathrm{CO}_{2}$ with $\mathrm{H}_{2}$ as the reductant via the reductive acetyl-CoA pathway (also known as Wood-Ljungdahl pathway, WLP) (Wood, 1991;
Wood and Ljungdahl, 1991). Three model organisms that have been studied in detail are Moorella thermoacetica, A. woodii, and Clostridium ljungdahlii. As these bacteria grow simply on $\mathrm{CO}_{2}$ and $\mathrm{H}_{2}$ without any external carbon source added, this mode of metabolism must be coupled to net ATP formation.

A. woodii as a model organism has been studied in detail to answer how energy is conserved during acetogenesis (Schuchmann and Müller, 2014). This unearthed surprising enzyme complexes that are unique in their diversity of the reactions they catalyze as well as their working mechanisms. Three such enzyme complexes are the Rnf complex, an FBEB hydrogenase and a $\mathrm{H}_{2}$-dependent $\mathrm{CO}_{2}$ reductase. A. woodii employs a sodium ion-dependent ferredoxin: NADoxidoreductase (Rnf complex) that couples the exergonic oxidation of reduced ferredoxin $\left(\mathrm{E}^{0}, \sim-450 \mathrm{mV}\right)$ with $\mathrm{NAD}^{+}$ $\left(\mathrm{E}^{0}=-320 \mathrm{mV}\right)$ to the generation of a transmembrane electrochemical $\mathrm{Na}^{+}$gradient (Figure 1B). The difference in the redox potential of ferredoxin and $\mathrm{NAD}^{+} / \mathrm{NADH}$ allows the pumping of $\mathrm{Na}^{+}$over the cytoplasmic membrane resulting in a $\mathrm{Na}^{+}$gradient that then drives the synthesis of ATP via the well-characterized $\mathrm{Na}^{+} \mathrm{F}_{1} \mathrm{~F}_{\mathrm{O}}$-ATP synthase (Spruth et al., 1995). Therefore, to drive energy conservation catalyzed by the Rnf complex, ferredoxin needs to be reduced. A. woodii solves this problem by using a FBEB uptake hydrogenase (Schuchmann and Müller, 2012) which is quite similar to the electron confurcating hydrogenases from T. maritima or R. albus (Zheng et al., 2014). 


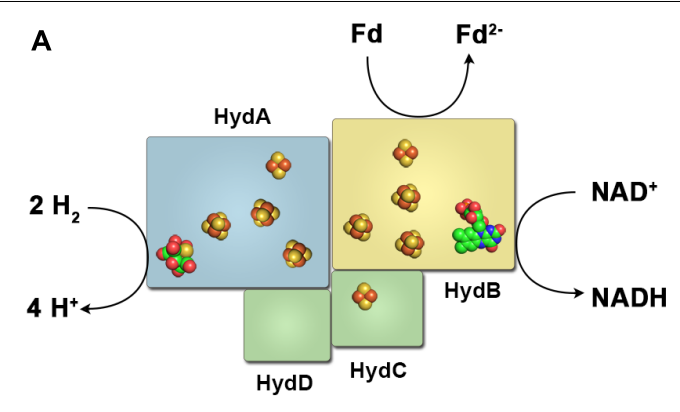

A. woodii

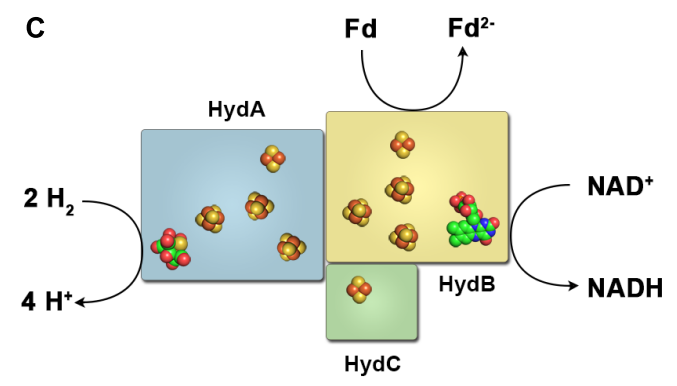

M. thermoacetica

[4Fe4S] cluster
[2Fe2S] cluster

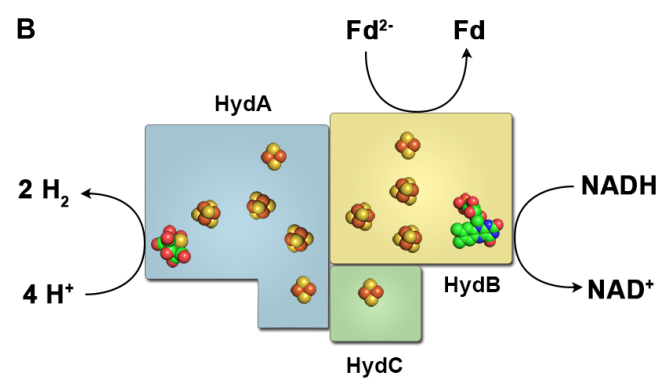

T. maritima

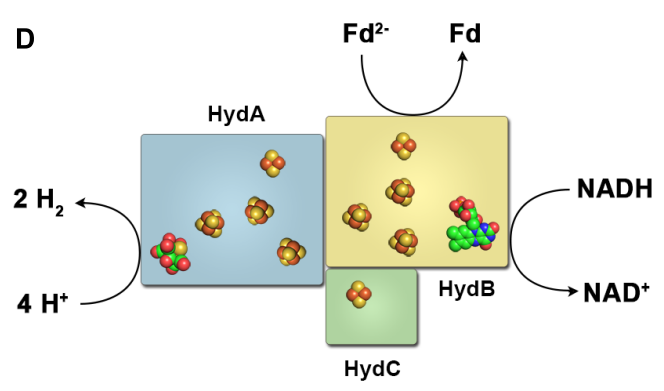

R. albus

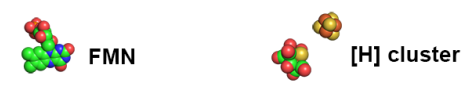

FIGURE 2 | Diversity of the subunit architecture and cofactor content of electron bifurcating and confurcating hydrogenases. Enzymes of this class have been isolated and characterized from A. woodii (A), T. maritima (B), M. thermoacetica (C) and R. albus (D). All enzymes contain the subunits HydA, harboring the active site, the putative flavin-containing and NAD-binding subunit HydB, and the putative electron-transferring subunit HydC. A. woodii contains the additional subunit HydD. The arrangement of the iron-sulfur clusters and the binding site for ferredoxin are chosen arbitrary. Fd, ferredoxin.

However, in case of chemolitotrophic growth, $\mathrm{H}_{2}$ is oxidized to reduce both $\mathrm{NAD}^{+}$and ferredoxin. The hydrogenase couples the exergonic oxidation of $\mathrm{H}_{2}\left(\mathrm{E}^{0}=-414 \mathrm{mV}\right)$ with $\mathrm{NAD}^{+}$ $\left(\mathrm{E}^{0}=-320 \mathrm{mV}\right)$ to the endergonic reduction of ferredoxin $\left(\mathrm{E}^{0} \sim-450 \mathrm{mV}\right)$. Reduced ferredoxin is used in two different reactions, one to reduce $\mathrm{CO}_{2}$ to $\mathrm{CO}\left(\mathrm{E}^{0}=-520 \mathrm{mV}\right)$ in the WLP and secondly to transfer electrons via the Rnf to $\mathrm{NAD}^{+}$, resulting in a $\mathrm{Na}^{+}$gradient (Biegel and Müller, 2010, 2011; Biegel et al., 2011). However, reaching the very low reduction potential for $\mathrm{CO}_{2}$ to $\mathrm{CO}$ reduction is difficult even at very high $\mathrm{H}_{2}$ partial pressure $\left(10^{5} \mathrm{~Pa}\right)$. FBEB provides an elegant solution by providing reduced ferredoxin with a more negative redox potential than the initial electron donor $\mathrm{H}_{2}$. The same is true when $A$. woodii is grown on methanol, where FBEB hydrogenase provides the extra reduced ferredoxin which is then used for $\mathrm{CO}_{2}$ reduction (Kremp et al., 2018).

The hydrogenase of $A$. woodii has been studied in the context of the autotrophic metabolism where its function is $\mathrm{H}_{2}$ oxidation. Besides, further insights into the non-autotrophic metabolism of $A$. woodii have revealed that the enzyme may function as a $\mathrm{H}_{2}$-evolving (electron bifurcating) hydrogenase as well. For example, when $A$. woodii grows on ethanol, only $\mathrm{NADH}$ is produced when ethanol is oxidized to acetyl-CoA. One part of the NADH is oxidized at the Rnf complex reducing ferredoxin. This reduced ferredoxin is then used with the other part of $\mathrm{NADH}$ by the hydrogenase to produce $\mathrm{H}_{2}$ for the first step of the WLP (Figure 1B) (Bertsch et al., 2015). So, the electronbifurcating/confurcating hydrogenase from $A$. woodii provides a nice example how anaerobes have evolved their metabolic enzymes which serves the purpose of both uptake and evolving $\mathrm{H}_{2}$ when needed in two different modes of energy metabolism.

\section{COFACTOR AND SUBUNIT ARCHITECTURE OF FBEB HYDROGENASES}

The $\mathrm{H}_{2}$ forming hydrogenases from T. maritima, R. albus, and M. thermoacetica (Wang et al., 2013b) and the $\mathrm{H}_{2}$ uptake/forming hydrogenase from $A$. woodii possess quite similar subunit compositions (Figure 2). All four enzymes are composed of the three subunits Hyd A $(\sim 64 \mathrm{kDa})$, Hyd B $(\sim 65 \mathrm{kDa})$ and Hyd $\mathrm{C}(\sim 14 \mathrm{kDa})$. HydA from T. maritima is larger compared to its counterpart by having a size of $73 \mathrm{kDa}$ putatively containing 

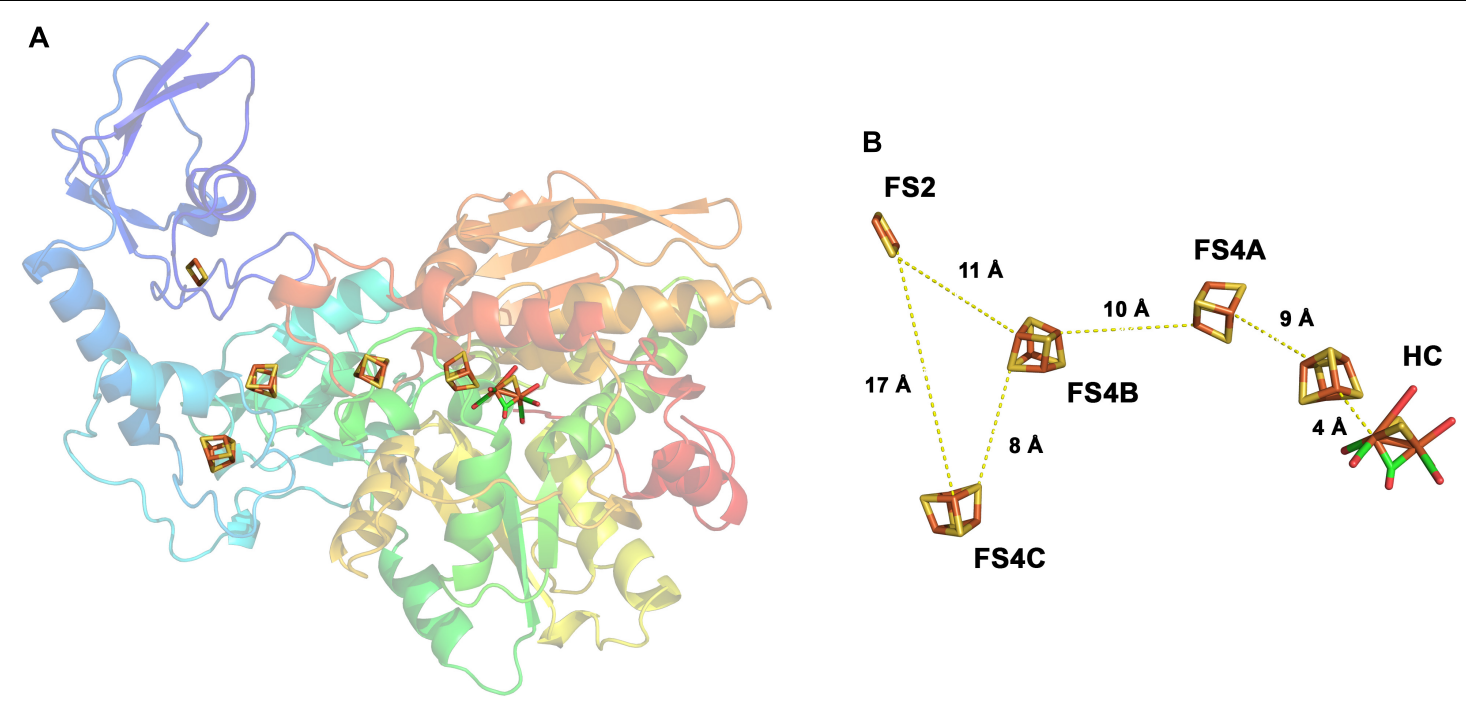

FIGURE 3 | Structure of the monomeric ferredoxin-dependent hydrogenase of $C$. pasteurianum. The 3D structure has been solved at $1.8 \AA$ resolution (1FEH, RSCB PDB database). The monomeric enzyme contains the $\mathrm{H}$-cluster typical for [FeFe] hydrogenases including the auxiliary [4Fe-4S] cluster. In addition, one [2Fe-2S]and three [4Fe-4S] clusters are bound in the enzyme (A). The iron-sulfur centers are arranged in a forked architecture with cluster FS2 being too far away from FS4C for direct electron transfer (B). FS2 and FS4C are both close enough to FS4B for electron transfer. HC, H-cluster. Modified from Peters et al. (1998).

an additional $[2 \mathrm{Fe}-2 \mathrm{~S}]$ cluster. Another exception is that the A. woodii hydrogenase has an extra subunit $\mathrm{HydD}(\sim 15 \mathrm{kDa})$ which is predicted to contain no cofactor (Schuchmann and Müller, 2012, 2014). On amino acid sequence comparison, HydA finds the closest similarity to the monomeric [FeFe] hydrogenase from C. pasteurianum (Figure 3). The first crystal structure of the $[\mathrm{FeFe}]$ hydrogenase from C. pasteurianum $\mathrm{CpI}$ was reported by Peters et al. (1998). The overall structure of the core domain consists of the $\mathrm{H}$-cluster (the active site of [FeFe] hydrogenases catalyzing $\mathrm{H}_{2}$ oxidation) including a diiron subcluster and one [4Fe-4S] cluster connected via a cysteine residue as found conserved in most of the [FeFe] hydrogenases. The diiron metals are coordinated by $\mathrm{CN}^{-}$and $\mathrm{CO}$, while the proximal $\mathrm{Fe}$ is linked to a cubane $[4 \mathrm{Fe}-4 \mathrm{~S}]$ cluster via a cysteine. The $[4 \mathrm{Fe}-$ $4 \mathrm{~S}]$ is around $4 \AA$ apart from the di-iron center. Apart from the $\mathrm{H}_{2}$-activating domain the domain interacting with the activesite domain contains two [4Fe-4S] clusters named as FS4A and FS4B (Figure 3). FS4A is $9 \AA$ apart from the H-cluster thus the direct electron carrier to or from the $\mathrm{H}$-cluster. FS4A is around $10 \AA$ apart from FS4B cluster and thus in line to the putative electron transfer pathway. There are two additional domains, one containing a [2Fe-2S] cluster named FS2 (11 ̊ from FS4B), the other contains a single $[4 \mathrm{Fe}-4 \mathrm{~S}]$ cluster called FS4C. FS4C has an unusual three cysteine and one histidine ligation. The two clusters FS4C and FS2 exhibit a forked architecture, where FS2 is far away from the direct line of electron transfer from FS4C. Most probably, FS4C directly gets electron from FS4B and finally transfers electrons to ferredoxin. A recent study using protein-protein docking modeling and NMR studies of electron transfer complex formation between the photosynthetic electron-transfer ferredoxin (PetF) containing a [2Fe-2S] cluster and the hydrogenase HydAl from the microalga $C$. reinhardtii revealed PetF to interact with HydA1 near to FS4C (Chang et al.,
2007; Rumpel et al., 2015). The function of FS2 and the forked orientation of the possible electron transfer chains is puzzling, especially in the context of an electron bifurcating enzyme.

Assuming a similar structural organization and cofactor content in the FBEB hydrogenases, HydA is predicted as the catalytic subunit for $\mathrm{H}_{2}$ oxidation. It contains the $\mathrm{H}$-cluster which is the site for $\mathrm{H}_{2}$ activation, one $[2 \mathrm{Fe}-2 \mathrm{~S}]$ and three [4Fe$4 \mathrm{~S}$ ] clusters. HydB has closest similarity to the NADH binding subunit NuoF of NADH-quinone oxidoreductase from E. coli, and is predicted to contain one $\mathrm{FMN}$, one $[2 \mathrm{Fe}-2 \mathrm{~S}]$ and three [4Fe-4S] clusters. HydC, which is related to NuoE, contains only one $[2 \mathrm{Fe}-2 \mathrm{~S}]$ cluster.

\section{A POSSIBLE ELECTRON PATHWAY IN FBEB HYDROGENASES}

How can the electron flow from $\mathrm{H}_{2}$ to $\mathrm{NAD}^{+}$and $\mathrm{H}_{2}$ to ferredoxin be energetically coupled within these multimeric hydrogenases? Until now the basis of FBEB has been revealed in other enzyme complexes like the Etf/Bcd complex from Acidaminococcus fermentans (Chowdhury et al., 2014, 2016), C. difficile (Demmer et al., 2017) and Megasphaera elsdenii (Chowdhury et al., 2015), LctBCD and CarCDE of A. woodii (Bertsch et al., 2013; Weghoff et al., 2015) and the Nfn transhydrogenase from T. maritima (Demmer et al., 2015), Pyrococcus furiosus (Lubner et al., 2017), FixABCX of Azotobacter vinelandii (Ledbetter et al., 2017) and HdrABC-MvhAGD from the thermophilic methanogenic archaeon Methanothermococcus thermolithotrophicus (Wagner et al., 2017). However, FBEB hydrogenases represent a very special case. FBEB enzymes so far all are proposed to contain a flavin having special redox properties. Flavins have three different redox potentials for the 

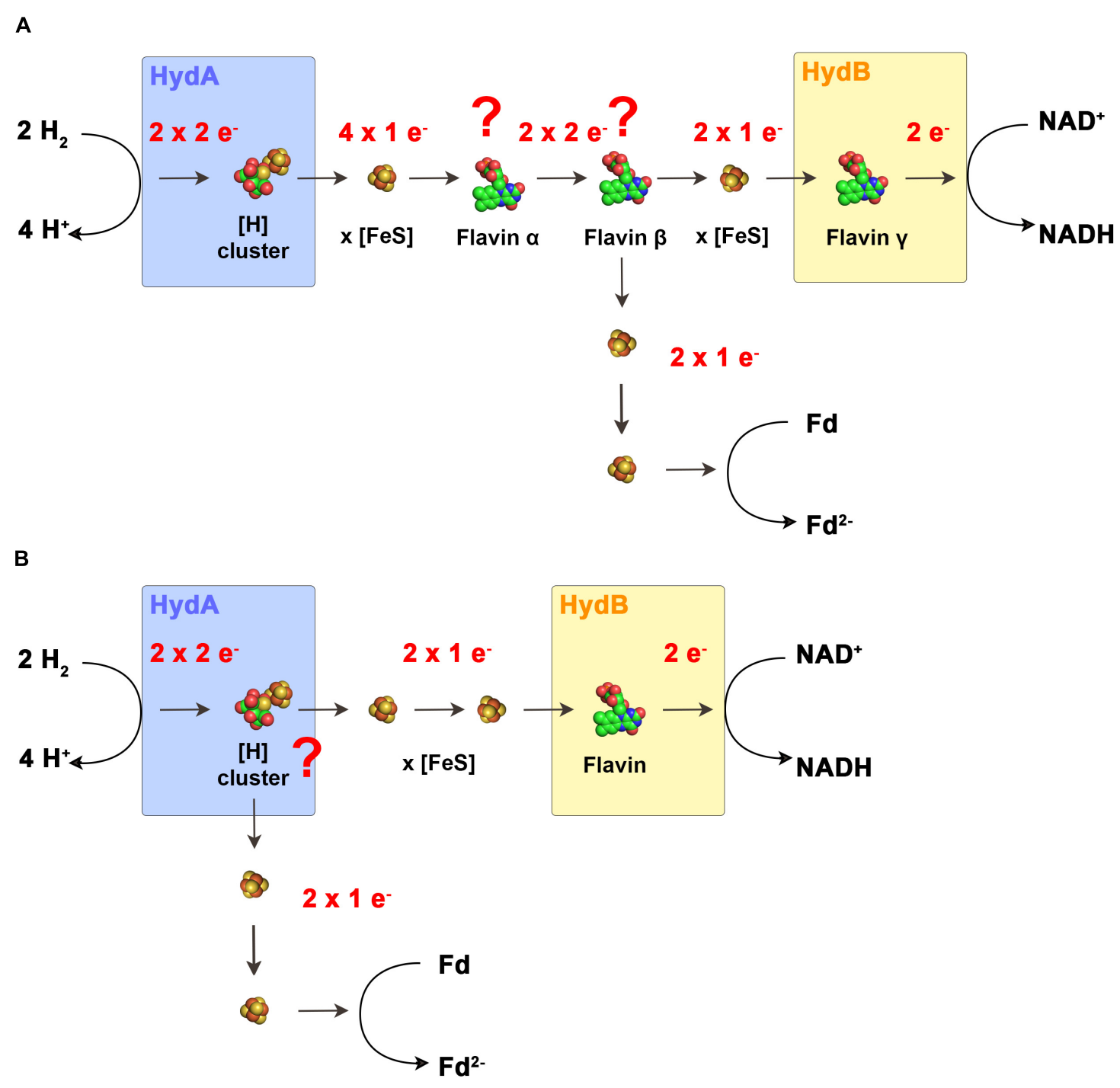

FIGURE 4 | Models for the electron flow in electron bifurcating hydrogenases. In the scenario that electron-bifurcation is facilitated by a flavin (A) according to the standard model of FBEB, the enzymes would have to contain two additional flavins that cannot be predicted from the primary structure. Flavin $\alpha$ functions as switch from one electron transferring iron-sulfur clusters to the actual bifurcating flavin $\beta$. Here, the two electrons are bifurcated to other iron-sulfur clusters and to the final acceptors. Flavin $\gamma$ functions as switch from the one electron transferring iron-sulfur clusters to NAD ${ }^{+}$. In the second scenario (B). The $\mathrm{H}$-cluster is the site of electron bifurcation. Here only one flavin is required for the switch from the one electron transferring iron-sulfur clusters to NAD ${ }^{+}$. Fd, ferredoxin.

three possible redox reactions:

$$
\begin{gathered}
F M N+1 e^{-} \rightleftharpoons F M N^{\circ} \quad\left(E_{1}\right) \\
F M N^{\circ}+1 e^{-}+2 H^{+} \rightleftharpoons F_{2} \quad\left(E_{2}\right) \\
F M N+2 e^{-}+2 H^{+} \rightleftharpoons F_{2} H_{2} \quad\left(E_{3}\right)
\end{gathered}
$$

In "standard" flavins the midpoint potential of $\mathrm{E}_{1}$ is more positive than $E_{2}$. In FBEB enzymes the flavin is supposed to have a "crossed" redox potential meaning that $\mathrm{E}_{1}$ is more negative than $\mathrm{E}_{2}$ (Nitschke and Russell, 2012). The two-electron redox potential $\left(E_{3}\right)$ is supposed to be between, meaning the average, of $E_{1}$ and
$\mathrm{E}_{2}$. Therefore, the flavin can be reduced in a two-electron transfer reaction by the electron donor $\left(\mathrm{E}_{3}\right)$ followed by the first electron being transferred to the more positive electron acceptor (e.g., $\left.\mathrm{NAD}^{+}\right)\left(\mathrm{E}_{2}\right)$ leaving behind a highly reactive $F M N^{\circ}$ that can now transfer the second electron to the more negative electron acceptor (e.g., ferredoxin) $\left(\mathrm{E}_{1}\right)$ (Demmer et al., 2017; Baymann et al., 2018; Buckel and Thauer, 2018a).

Based on the current knowledge, FBEB hydrogenases have only one predicted flavin in $\mathrm{HydB}$ which is required for the switch from a two-electron carrier (NADH) to a one electron carrier (iron-sulfur cluster), a typical function of "standard" flavins. Therefore, Buckel and Thauer (2013) proposed that FBEB hydrogenases need to have an additional "special" flavin to perform the electron bifurcation reaction. To function in 
accordance to the standard model of FBEB, the electron flow would look like the following (Figure 4A): $\mathrm{H}_{2}$ is oxidized at the $\mathrm{H}$-cluster followed by the electron transfer to the iron-sulfur clusters. $\mathrm{H}_{2}$ has a redox potential in between $\mathrm{NAD}^{+}$and ferredoxin, therefore, it must reduce the flavin with a two-electron transfer reaction to reach the flavin redox potential $\mathrm{E}_{3}$. However, since iron sulfur clusters can only transfer one electron at a time we therefore speculate that in this model a second flavin (flavin $\alpha$ ) would be required for the additional one electron/two electron switch. Then, the "special" flavin (flavin $\beta$ ) can transfer the first electron to the iron sulfur cluster leading to $\mathrm{NAD}^{+}$leaving behind a highly reactive flavin radical that transfers the second electron to the iron-sulfur clusters leading to ferredoxin. The third flavin (flavin $\gamma$ ) is then needed for the second one electron/two electron switch from the iron sulfur clusters to $\mathrm{NAD}^{+}$.

Of the characterized FBEB enzymes HdrABC-MvhAGD from $M$. thermolithotrophicus, a complex of a multimeric heterodisulfide reductase and a $[\mathrm{NiFe}]$ hydrogenase represents a special case (Wagner et al., 2017). The flavin proposed to be responsible for electron bifurcation is assumed to receive both electrons from $\mathrm{H}_{2}$ in two single electron transfer steps in contrast to a two electron transfer from a hydride donor. This is in contrast to the current model of the energetic landscape required for electron bifurcating flavins. However, if electron bifurcation is possible by a flavin connected to three one electron donors/acceptors in the form of iron-sulfur clusters, this could also be the case in FBEB [FeFe] hydrogenases and would render the presence of the hypothetically proposed flavin $\alpha$ redundant.

The aforementioned model assumes the presence of additional flavin binding sites that are not predicted by the amino acid sequence. The flavin content of all isolated FBEB hydrogenases could not be determined or not reported since the flavins are only loosely attached and must be added to the buffers for activity and got immediately lost when left out of the buffers. Assuming that the additional flavins do not exist, a completely new mechanism of FBEB must be present in FBEB hydrogenases. First Nitschke and Russell (2012) raised the possibility that also some metal centers could have crossed redox potentials and could potentially catalyze the same reaction as catalyzed by the flavin cofactor. Peters et al. (2018) took up this exciting possibility and proposed for electron bifurcating hydrogenases that since the FMN cannot be the site for electron bifurcation, the H-cluster could be the possible site for the electron bifurcation reaction. In their proposal, the electrons flow from the $\mathrm{H}$-cluster directly to two different accepting iron-sulfur clusters with different redox potentials. The first string of $\mathrm{Fe}-\mathrm{S}$ clusters transfers the electrons from the H-cluster to ferredoxin. The other string of iron-sulfur clusters plus the single flavin transfers the electrons from the H-cluster to $\mathrm{NAD}^{+}$(Figure 4B). However, so far no metal center has been shown to accommodate the special properties necessary for electron bifurcation, therefore, this model would lead to a completely new field of enzyme mechanism catalyzed by metal centers.

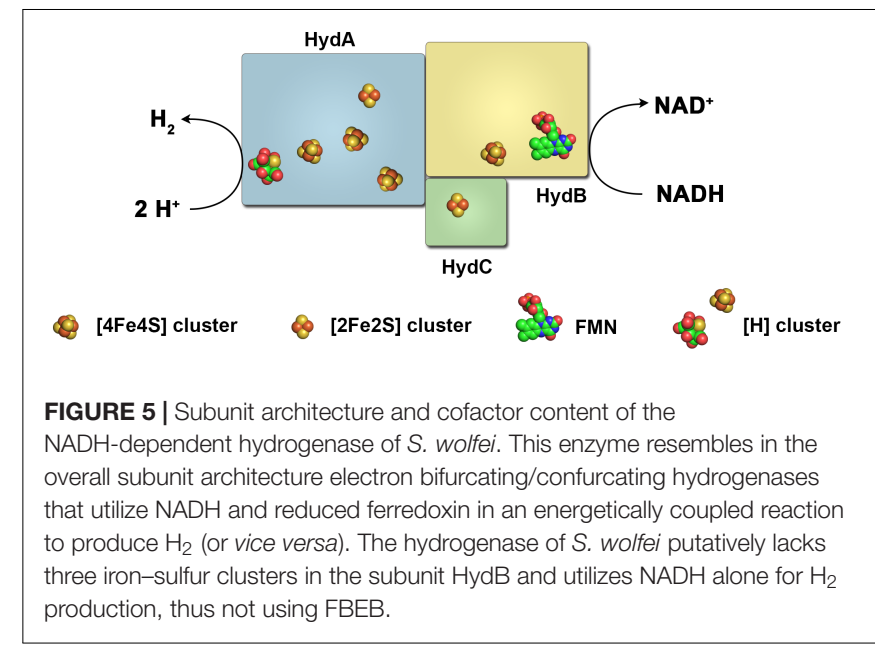

\section{THE CURIOUS CASE OF THE NAD ${ }^{+}$-DEPENDENT HYDROGENASE FROM Syntrophomonas wolfei}

Recently, a hydrogenase has been purified from the syntrophic bacterium $S$. wolfei that very much resembles all known FBEB hydrogenases discussed so far, however, does not show FBEB (Losey et al., 2017). Therefore, comparison of this enzyme to the other ones might be helpful to unravel the mechanism of FBEB hydrogenases. The purified recombinant hydrogenase (Hyd1ABC) of $\mathrm{S}$. wolfei showed $\mathrm{H}_{2}$ production from NADH alone, uncoupled to ferredoxin. The recombinant enzyme had a very high $\mathrm{H}_{2}$-dependent: methyl-viologen reducing activity $(3,340 \mathrm{U} / \mathrm{mg}), \mathrm{H}_{2}$-dependent $\mathrm{NAD}^{+}$reducing activity (94.5 U/mg) and catalyzed $\mathrm{H}_{2}$ production from $\mathrm{NADH}$ with a specific activity of $6.6 \mathrm{U} / \mathrm{mg}$. The enzyme is a trimeric protein complex composed of HydA1 (63 kDa), HydB1 (43 kDa), and HydC1 (17.5 kDa) (Figure 5). It contains five [4Fe-4S], two [2Fe-2S] clusters, and one H-cluster. The flavin content was determined to be $0.7 \mathrm{~mol}$ of FMN per mole of enzyme. The Hyd1ABC subunits share close similarity to those of the earlier discussed FBEB hydrogenases. HydA1 is, again, similar to the monomeric C. pasteurianum hydrogenase, putatively containing the $\mathrm{H}$-cluster, $3[4 \mathrm{Fe}-4 \mathrm{~S}]$ clusters and one [2Fe-2S] cluster and is the site for $\mathrm{H}_{2}$ formation. $\mathrm{HydC1}$ has been predicted to contain one $[2 \mathrm{Fe}-2 \mathrm{~S}]$ cluster. Nevertheless, the question arose why this enzyme Hyd1ABC of $S$. wolfei, though having the same organization of subunits like FBEB hydrogenases, does not oxidize/reduce ferredoxin. One reason that the authors discuss is the lack of one $[2 \mathrm{Fe}-2 \mathrm{~S}]$ cluster putatively bound in a N-terminal domain of HydB of FBEB hydrogenases as well as the lack of one $[4 \mathrm{Fe}-4 \mathrm{~S}]$ cluster putatively bound in the $\mathrm{C}$-terminal domain of $\mathrm{HydB}$ of FBEB hydrogenases. In fact, S. wolfei HydB1 is much smaller than HydB of other FBEB hydrogenases $(43 \mathrm{kDa}$ compared to $63 \mathrm{kDa}$ ). Electrons are supposed to be transferred from NADH via the FMN to the proximal [4Fe-4S] cluster, and further transferred via the $[\mathrm{Fe}-\mathrm{S}]$ clusters in HydA1 to the $\mathrm{H}$-cluster to reduce protons to $\mathrm{H}_{2}$. The $\mathrm{S}$. wolfei hydrogenase 
might be a step in evolution away from FBEB hydrogenases to "standard" hydrogenases or, possibly, the other way around. In any case, solving the structure of this enzyme and comparing it to a bifurcating hydrogenase might unravel factors essential for the energetic coupling within the bifurcating enzymes.

\section{FORMATE DEHYDROGENASE COUPLED HYDROGENASES}

Protons can be used by microorganisms as ubiquitously available electron acceptor to get rid of excess reducing equivalents. A similar function is played by $\mathrm{CO}_{2}$. In anoxic environments, $\mathrm{CO}_{2}$ or $\mathrm{HCO}_{3}{ }^{-}$is ubiquitously available (50-100 $\mathrm{mM} \mathrm{HCO}_{3}{ }^{-}$in lake sediments, $200-400 \mathrm{mM} \mathrm{HCO}_{3}{ }^{-}$in biogas reactors) and can be used as electron acceptor yielding formic acid/formate (Crable et al., 2011; Schink et al., 2017). Interestingly, the redox potential of the $\mathrm{CO}_{2}$ /formate couple of $-432 \mathrm{mV}$ is very close to the $\mathrm{H}^{+} / \mathrm{H}_{2}$ couple rendering both electron acceptors energetically very similar. Therefore, it is not surprising that both $\mathrm{H}_{2}$ and formate have been observed as important electron carriers in anoxic environments with often interchangeable functions (Thiele and Zeikus, 1988; Stams and Plugge, 2009; Schink et al., 2017; Montag and Schink, 2018). However, for a long time little was known on how the two pools of high energy redox mediators are connected with each other. In the past years these two compounds gained increasing interest due to their potential as electron donors for biofuel production, as energy carriers for mobile applications or issues like $\mathrm{H}_{2}$ storage. This has led to discoveries of novel enzymes but also so far unknown organisms that connect and utilize these two redox mediators.

\section{FORMATE HYDROGEN LYASE OF E. coli}

Already in 1932 Stephenson and Stickland discovered that whole cells of $E$. coli grown in the presence of formate decompose formate into $\mathrm{H}_{2}+\mathrm{CO}_{2}$ (Stephenson and Stickland, 1931, 1932). They named the supposed enzyme system formate hydrogen lyase (FHL). When growing under anoxic conditions in the absence of an alternative electron acceptor $E$. coli produces formic acid during mixed acid fermentation from pyruvate catalyzed by pyruvate-formate lyase which is then exported from the cytoplasm by the channels FocA and/or FocB (Clark, 1989; Sawers et al., 2004; Wang et al., 2009; Lu et al., 2011; Trchounian and Trchounian, 2014; Hakobyan et al., 2018). Formic acid $\left(\mathrm{pK}_{\mathrm{S}}=3.7\right)$ dissociates to formate and leads to an acidification of the environment. A drop in the $\mathrm{pH}$ together with the accumulation of formate leads to subsequent import of formate again and the induction of expression of the genes coding for the FHL enzyme. FHL then oxidizes formate to $\mathrm{H}_{2}+\mathrm{CO}_{2}$ followed by reoxidation of $\mathrm{H}_{2}$ by other membrane bound hydrogenases of E. coli that transfer the electrons to the quinone pool (Rossmann et al., 1991; Sawers, 1994; Sawers, 2005; Pinske and Sawers, 2016).

Stephenson and Stickland assumed the enzymes to be a combination of formate dehydrogenase and hydrogenase. Genetic and physiological studies have confirmed this assumption and shown that the FHL of E. coli consist of a formate dehydrogenase bound to a membrane integral multimeric hydrogenase located in the cytoplasmic membrane (Zinoni et al., 1986; Böhm et al., 1990; Rossmann et al., 1991; Sauter et al., 1992). However, isolation of the whole FHL complex was achieved only recently by McDowall et al. (2014). The enzyme complex consists of two membrane integral subunits and five soluble subunits. The soluble subunits $\mathrm{HycE}$ and $\mathrm{HycG}$ represent the large $(65 \mathrm{kDa})$ and small $(20 \mathrm{kDa})$ subunits of the [NiFe]-hydrogenase termed E. coli hydrogenase-3 (Hyd-3) (Figure 6A). Formate is oxidized by the subunit FdhF (also called formate dehydrogenase H) (Axley et al., 1990; Gladyshev et al., 1996; Boyington et al., 1997).

The FHL complex shows high similarity to a group of similar membrane bound hydrogenases now called energy-converting hydrogenases (Ech). These enzymes are found in many anaerobic and facultative anaerobic bacteria and $\mathrm{H}_{2}$ formation is coupled to different electron donors such as reduced ferredoxin or $\mathrm{CO}$, facilitated by auxiliary subunits (Fox et al., 1996; Künkel et al., 1998; Meuer et al., 1999; Sapra et al., 2000; Soboh et al., 2002). It has been assumed that Ech hydrogenases couple $\mathrm{H}_{2}$ formation to the translocation of ions across the membrane. Experimental proof for this concept was established using inverted membrane vesicles of the methanogenic archaeon Methanosarcina mazei (Welte et al., 2010a,b). However, whether the FHL complex of $E$. coli is also coupled to energy conservation has been a matter of debate for many years (Bagramyan and Martirosov, 1989; Trchounian et al., 1997, 2000, 2011; Hakobyan et al., 2005; McDowall et al., 2014; Trchounian and Sawers, 2014; Pinske and Sargent, 2016).

FHL couples the two half reactions

$$
\text { formate }+\mathrm{H}^{+} \rightleftharpoons \mathrm{CO}_{2}+2 e^{-}+2 \mathrm{H}^{+} \quad E^{0^{\prime}}=-432 \mathrm{mV}
$$

and

$$
2 \mathrm{H}^{+}+2 e^{-} \rightleftharpoons \mathrm{H}_{2} \quad E^{0^{\prime}}=-414 m \mathrm{~m}
$$

resulting in the net reaction

$$
\text { formate }+\mathrm{H}^{+} \rightleftharpoons \mathrm{H}_{2}+\mathrm{CO}_{2}
$$

Under standard conditions, the free energy change of Eq. (9) is only $-3.5 \mathrm{~kJ} \mathrm{~mol}^{-1}$ (Thauer et al., 1977). Thus, based on the $\Delta \mathrm{G}^{0}$ ' value, the FHL reaction should be fully reversible under physiological conditions, however, the enzyme shows a strong bias toward formate oxidation. Values for in vitro turnover frequency (TOF) for FHL activity was reported between $1,200 \mathrm{~h}^{-1}$ and $1,920 \mathrm{~h}^{-1}$ (McDowall et al., 2014; Pinske and Sargent, 2016) whereas the reverse reaction, formate formation from $\mathrm{H}_{2}+\mathrm{CO}_{2}$ was only observed with an apparent TOFs of only $202 \mathrm{~h}^{-1}$ (measured in a discontinuous one point assay and reported as $3.25 \mu \mathrm{mol}$ formate produced after $5 \mathrm{~h}$ with $370 \mu \mathrm{g}$ of enzyme) (Pinske and Sargent, 2016). This bias could not be explained by the catalytic properties of FdhF and Hyd-3 that have been analyzed separately and show high activities in both reaction directions (Bassegoda et al., 2014; McDowall et al., 2014). In addition to both active sites a factor determining the bias in one or the other direction could be the thermodynamic landscape 


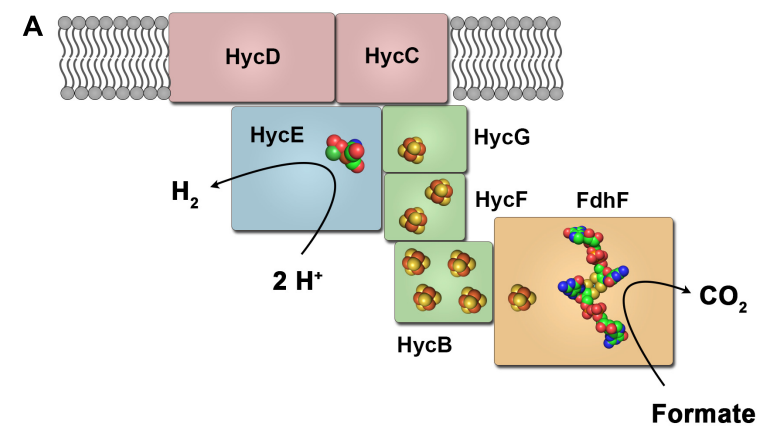

[4Fe4S] cluster

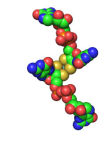

Mo / W bis pyranopterin guanosine dinucleotide
B

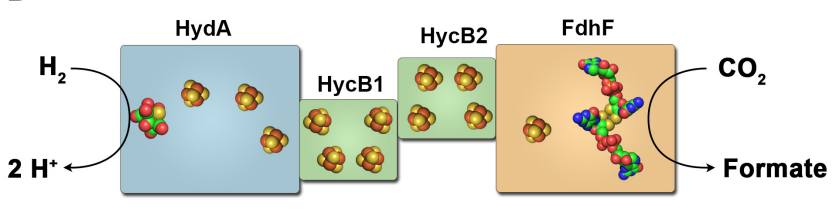

FIGURE 6 | Model of the structure of formate dehydrogenase coupled hydrogenases. FHL of E. coli (A) has the physiological function of formate oxidation coupled to $\mathrm{H}_{2}$ formation. The FHL consist of a [NiFe] hydrogenase coupled to a formate dehydrogenase and membrane integral subunits. In contrast, the HDCR of $A$. woodii (B) is composed of a [FeFe] hydrogenase coupled to a formate dehydrogenase and catalyzes reversible $\mathrm{CO}_{2}$ reduction with $\mathrm{H}_{2}$ as electron donor.

of the connecting iron-sulfur clusters. In addition, the membrane attachment of this enzyme complex and the connection to the enzyme activity is still puzzling (Bagramyan and Martirosov, 1989; Trchounian et al., 1997, 2000, 2011; Hakobyan et al., 2005; McDowall et al., 2014; Trchounian and Sawers, 2014; Pinske and Sargent, 2016). From a physiological point of view, the bias could be a remnant of evolution since there is no physiological situation where $E$. coli would use the reverse reaction to produce formate from $\mathrm{CO}_{2}$ since this organism is not able to utilize formate further in the metabolism.

\section{HYDROGEN-DEPENDENT $\mathrm{CO}_{2}$ REDUCTASES}

For many years, FHL was the only enzyme complex known that connects the electron carriers $\mathrm{H}_{2}$ and formate but this enzyme shows a strong bias toward formate oxidation. Did evolution also bring up enzymes adapted for the reverse reaction? Efficient catalysts for hydrogenation of $\mathrm{CO}_{2}$ are highly soughtafter (Appel et al., 2013; Beller and Bornscheuer, 2014; Wang et al., 2015). These could be used for $\mathrm{CO}_{2}$ conversion technologies for carbon capture, for $\mathrm{CO}_{2}$-based synthesis or for $\mathrm{H}_{2}$ storage (Yishai et al., 2016; Preuster et al., 2017b; Bulushev and Ross, 2018). Many homogeneous and heterogenous chemical catalyst have been developed, however, often requiring high temperatures and pressures (Fujita et al., 2013; Wang et al., 2015). In biological systems, of the six pathways known for $\mathrm{CO}_{2}$ fixation, only the WLP proceeds via direct reduction of $\mathrm{CO}_{2}$ to formate catalyzed by formate dehydrogenases (Fuchs, 2011). In 2013, a formate dehydrogenase was isolated from the acetogenic bacterium A. woodii that was in complex with a hydrogenase, on first glance resembling the FHL of E. coli (Schuchmann and Müller, 2013). However, in contrast to FHL, the enzyme was lacking membrane integral subunits. When isolated, the enzyme contained only four subunits, one formate dehydrogenase, one hydrogenase and two iron-sulfur cluster rich subunits, identified as being encoded by genes found in one gene cluster (Figure 6B). The gene clusters contains in addition a gene coding for a second formate dehydrogenase, a gene for a third iron-sulfur cluster rich subunits and a gene designated as $f d h D$ (Poehlein et al., 2012; Schuchmann and Müller, 2013). The formate dehydrogenase FdhF2 as found in the isolated enzyme is a $80.1 \mathrm{kDa}$ protein with $59 \%$ identity to $\mathrm{FdhH}$ of the E. coli FHL aligning over the whole sequence of 713 amino acids. It has one predicted [4Fe-4S] cluster and a bis-PGD cofactor. ICP-MS identified $0.6 \mathrm{~mol}$ molybdenum but no tungsten per mol of isolated enzyme preparation agreeing with a mononuclear molybdenum bound to the bis-PGD cofactor thus classifying this enzyme as member of the dimethylsulfoxide reductase family within the Mo/W-bis PGD super-family (Schuchmann and Müller, 2013). At amino acid position 139, a selenocysteine is predicted which is in agreement with the determined selenium in the preparation. In contrast to E. coli $\mathrm{FHL}$, the [NiFe] hydrogenase subunits of FHL are substituted by the [FeFe] hydrogenase subunit HydA2 $(50.2 \mathrm{kDa})$. The sequence of this subunit contains the conserved regions typical for $\mathrm{H}$-cluster binding and aligns to amino acid region 201-572 of the monomeric ferredoxin-dependent [FeFe] hydrogenase of $C$. pasteurianum (Figure 3). In contrast to the C. pasteurianum enzyme, the $\mathrm{N}$-terminus containing one $[2 \mathrm{Fe}-$ $2 \mathrm{~S}]-$ and one [4Fe-4S] cluster is missing. In addition to the $\mathrm{H}$-cluster including the adjacent [4Fe-4S] cluster, the enzyme is predicted to contain two additional [4Fe-4S] clusters. HydA2 and FdhF2 are supposed to be connected by the two small electron transferring subunits $\mathrm{HycB} 2$ and HycB3 (18.9 and $20.1 \mathrm{kDa}$, respectively) containing 4 [4Fe-4S] clusters each (Figure 6B).

Enzymatic assays utilizing methyl viologen demonstrated that both FdhF2 as well as HydA2 were highly active in the isolated enzyme. $\mathrm{H}_{2}$ oxidation was catalyzed with a TOF of $30,474 \mathrm{~s}^{-1}$ (Schuchmann and Müller, 2013). The formate dehydrogenase subunit catalyzed formate oxidation with $1,693 \mathrm{~s}^{-1}$ and $\mathrm{CO}_{2}$ reduction with $372 \mathrm{~s}^{-1}$ also showing a bias for formate oxidation, 


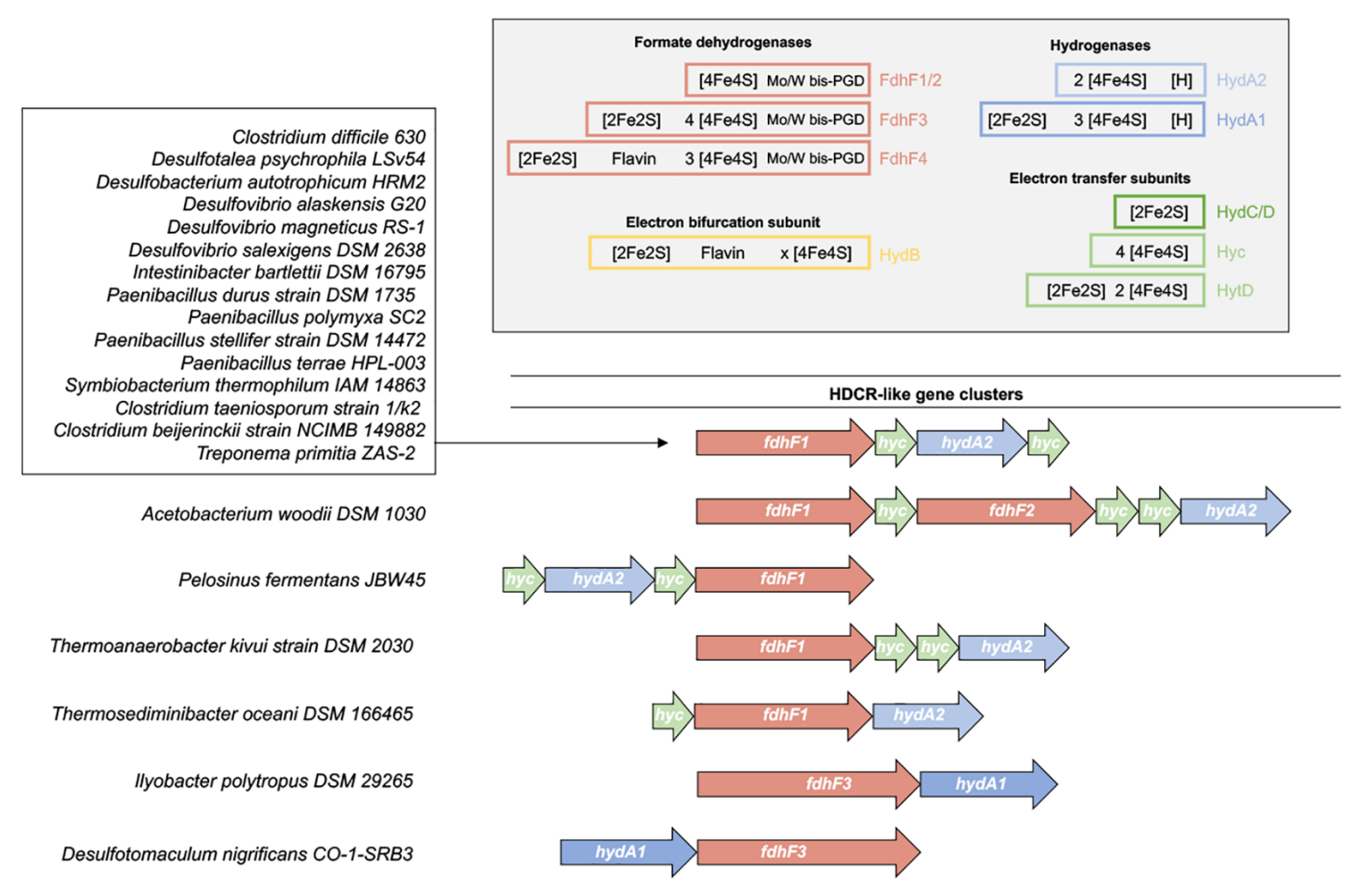

Cloacibacillus porcorum strain CL-841
Clostridium carboxidivorans P71

HDCR-like gene clusters with electron bifurcating modules

Peptoclostridium acidaminophilum DSM 39536

Clostridium autoethanogenum
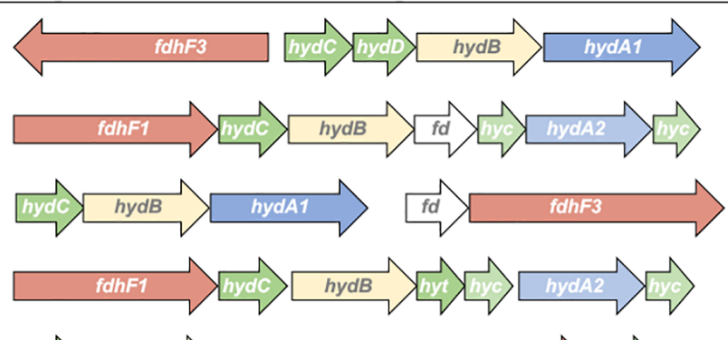

Dehalobacterium formicoaceticum strain DMC4

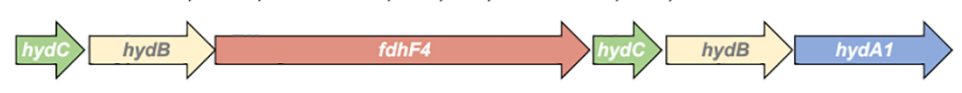

FIGURE 7 | Distribution of HDCR-like gene clusters. Fully sequenced bacterial genomes have been searched for HDCR-like gene clusters (Schwarz et al., 2018). Based on the gene cluster arrangement, the enzymes can be classified in HDCR-like enzyme complex without and with electron bifurcating modules. Predicted cofactors based on the primary sequence of each subunit are shown in the right top corner. For clarity, single genes disrupting the gene cluster in some organisms such as maturation genes (e.g., fdhD) or transposase are not shown.

however, not as severe as reported for $\mathrm{FdhH}$ of the FHL that showed no measurable $\mathrm{CO}_{2}$ reduction activity with soluble electron carriers. HydA2 has been analyzed by catalytic protein film electrochemistry by adsorbing the whole enzyme complex to an electrode (Ceccaldi et al., 2017). The hydrogenase is biased for proton reduction oxidizing $\mathrm{H}_{2} 10$ times slower than it reduces protons at $\mathrm{pH} 6$ as is typical for [FeFe] hydrogenases. However, this ratio defining the bias decreases with increasing $\mathrm{pH}$.

$\mathrm{K}_{\mathrm{M}}$ for $\mathrm{H}_{2}$ was determined to 0.24 atm $\left[\mathrm{K}_{\mathrm{i}}\left(\mathrm{H}_{2}\right)=6.4 \mathrm{~atm}\right]$, being three times lower than reported values for $C$. reinhardtii and Clostridium acetobutylicum and thus showing the highest affinity ever reported for a [FeFe] hydrogenase (Fourmond et al., 2013; Ceccaldi et al., 2017). In addition, HydA2 showed the surprising characteristic of being the first completely $\mathrm{CO}$ tolerant $[\mathrm{FeFe}]$ hydrogenase. Even though the enzyme is strongly inhibited by $\mathrm{CO}\left[\mathrm{K}_{\mathrm{i}}(\mathrm{CO})=0.11 \mu \mathrm{M}\right]$, it fully reactivates upon removal of $\mathrm{CO}$ which is in contrast to other [FeFe] hydrogenases where $\mathrm{CO}$ provokes irreversible damage to the H-cluster (Goldet et al., 2009; Baffert et al., 2011; Foster et al., 2012). This feature could be a result of the metabolism of $A$. woodii where $\mathrm{CO}$ is an intermediate of the reductive acetyl-CoA pathway (Schuchmann and Müller, 2014; Bertsch and Müller, 2015b).

Coupling of the formate dehydrogenase/hydrogenase complex of $A$. woodii was analyzed by incubating the isolated enzyme in the presence of formate. This lead to $\mathrm{H}_{2}$ production with a TOF of $142,212 \mathrm{~h}^{-1}$ (Schuchmann and Müller, 2013). Interestingly, 
this enzyme is fully reversible also catalyzing hydrogenation of $\mathrm{CO}_{2}$ at $30^{\circ} \mathrm{C}$ and 0.8 bar of $\mathrm{H}_{2}$ and 0.2 bar of $\mathrm{CO}_{2}$ with a TOF of $101,600 \mathrm{~h}^{-1}$ being significantly faster than the currently best known chemical catalysts (Hull et al., 2012; Jeletic et al., 2013; Wang et al., 2015; Eppinger and Huang, 2017). To distinguish the soluble enzyme complex from membrane bound FHL complexes that are weak catalysts for $\mathrm{CO}_{2}$ hydrogenation the enzyme was named hydrogen-dependent $\mathrm{CO}_{2}$ reductase (HDCR). As mentioned before, $\mathrm{CO}$ is a strong inhibitor of the hydrogenase activity (Goldet et al., 2009). Interestingly, the HDCR has an alternative electron entry site and can use reduced ferredoxin as electron donor to allow $\mathrm{CO}_{2}$ reduction even in the presence of $1 \mathrm{~atm} \mathrm{CO}$. However, this activity is 17 times slower than the hydrogen-dependent activity with a TOF of only $6,095 \mathrm{~h}^{-1}$ (Schuchmann and Müller, 2013). Noteworthy, further characterization of the HDCR revealed another interesting property of the enzyme. In vitro the HDCR of $A$. woodii reversibly polymerized into ordered filamentous structures of more than $0.1 \mu \mathrm{M}$ in length (Schuchmann et al., 2016). Divalent cations could be identified to promote the polymerization process and it was observed that the polymerized form of the enzyme was more active. The in vivo significance of this observation is unresolved.

As described before, the HDCR gene cluster of $A$. woodii contains a gene, $f d h F 1$, for a second formate dehydrogenase subunit with the corresponding electron transferring subunit $h y c B 1$. The deduced amino acid sequence of FdhF1 is to $80 \%$ identical to FdhF2 with the major exception being a cysteine in FdhF1 at position 139 where a selenocysteine is encoded in FdhF2. Metal-dependent formate dehydrogenases have been described with either selenocysteine or cysteine in the active site (Axley et al., 1990; Friedebold and Bowien, 1993; Raaijmakers et al., 2002; de Bok et al., 2003; Laukel et al., 2003). The lower $\mathrm{pK}_{\mathrm{a}}$ value of selenocysteine compared to cysteine is typically connected to a higher reactivity (Stadtman, 1996; Böck et al., 2005; Stock and Rother, 2009). Exchanging selenocysteine by cysteine in $\mathrm{FdhH}$ of $E$. coli let to a decrease in turnover number by over two orders of magnitude. However, the affinity for the substrate was increased in the cysteine variant as reflected by a lower $K_{M}$ value (Axley et al., 1991). There is no data on the different properties of FdhF1 and FdhF2 of A. woodii, however, the assumption is that in dependence on the presence of selenium in the environment the two subunits are produced differentially with the selenocysteine containing variant being the more active one. In another acetogenic bacterium, a spirochete from the termite gut, Treponema primitia, a gene cluster with similarity to the HDCR gene cluster was identified (Matson et al., 2010). It consists of the genes $f d h F_{c y s}$, two $h y c B$ genes, $f d h D$ and $h y d A$. Separated by 14 genes, a second $f d h F$ gene is encoded, containing a putative selenocysteine codon and a SECIS element $\left(f d h F_{\text {sec }}\right)$. Transcript analysis revealed a differential expression of $f d h F_{c y s}$ and $f d h F_{s e c}$ in dependence of selenium availability with up to 40 -fold change in transcript levels. Half-maximum decrease in transcript level of $f d h F_{c y s}$ was observed with less than $50 \mathrm{pM}$ sodium selenite, whereas $1.5 \mathrm{nM}$ sodium selenite were required for half-maximum increase in $f d h F_{s e c}$ transcript levels. Interestingly, only transcript levels downstream of the SECIS element were differentially expressed, whereas transcript upstream of the SECIS element did not show differential regulation (Matson et al., 2010).

\section{PHYSIOLOGY AND DIVERSITY OF HDCR COMPLEXES}

The first HDCR complex has been identified in the acetogenic bacterium A. woodii. Acetogenic bacteria utilize the WLP for energy conservation and carbon fixation, the only carbon fixation pathway that utilizes $\mathrm{CO}_{2}$ by direct reduction to formate. Therefore, this first reduction step of $\mathrm{CO}_{2}$ is essential for the metabolism of these bacteria. The redox potential of $\mathrm{CO}_{2} /$ formate of $-432 \mathrm{mV}$ limits the number of possible electron donors for this reaction. The first formate dehydrogenase characterized in an acetogenic bacterium was isolated from Moorella thermoacetica (Yamamoto et al., 1983). This heterotetrameric enzyme was the first enzyme described to contain tungsten and catalyzes $\mathrm{CO}_{2}$ reduction coupled to NADPH oxidation. The standard redox potential of $\mathrm{NADP}^{+} / \mathrm{NADPH}$ of $-340 \mathrm{mV}$ is too positive for $\mathrm{CO}_{2}$ reduction, however, in anaerobes the intracellular ratio of $\mathrm{NADP}^{+} / \mathrm{NADPH}$ is $1 / 40$ resulting in a redox potential of $-370 \mathrm{mV}$ (Sauer et al., 2004; Bennett et al., 2009). Insights into an increasing number of sequenced genomes of acetogenic bacteria has revealed that the genes encoding enzymes for the first reaction step of the WLP show a large diversity (Schuchmann and Müller, 2014; Bertsch and Müller, 2015a; Bengelsdorf et al., 2016). Therefore, the knowledge of the enzymes of $M$. thermoacetica could not be transferred to other acetogens. Characterization of $A$. woodii has revealed that it does not use NADPH but $\mathrm{H}_{2}$ as electron donor for $\mathrm{CO}_{2}$ reduction catalyzed by the HDCR. Energetically, the difference between NADPH and $\mathrm{H}_{2}$ is very small under physiological conditions. $\mathrm{H}_{2}$ is a stronger reductant under standard conditions $\left(\mathrm{E}^{0}=-414 \mathrm{mV}\right)$, however, at the minimum $\mathrm{H}_{2}$ pressures required by $A$. woodii to perform acetogenesis $(250 \mathrm{~Pa})$ the redox potential is only $-340 \mathrm{mV}$ (Poehlein et al., 2012). Under these conditions, the equilibrium concentration of formate is $0.1 \mathrm{mM}\left(\mathrm{CO}_{2}\right.$ at $\left.0.2 \times 10^{5} \mathrm{~Pa}, 30^{\circ} \mathrm{C}\right)$, in the range of the $\mathrm{K}_{\mathrm{M}}$ value of next enzyme of the pathway, the formyl-THF synthetase (Poehlein et al., 2012). Coupling $\mathrm{CO}_{2}$ reduction directly to $\mathrm{H}_{2}$ oxidation also energetically couples it directly to the external $\mathrm{H}_{2}$ partial pressure. A $\mathrm{H}_{2}$ pressure of $250 \mathrm{~Pa}$ is very high compared to the values observed in methanogenic environments of 1 to $10 \mathrm{~Pa} \mathrm{H}_{2}$ (Conrad et al., 1986; Seitz et al., 1990). Therefore, $\mathrm{CO}_{2}$ reduction by HDCR enzymes seems to be not competitive in methanogenic environments. However, the observation of reduced ferredoxin as alternative electron carrier could be a mechanism to overcome this limitation (in addition to the proposed bypass for $\mathrm{CO}$ inhibition of the hydrogenase as discussed before). On the other hand, utilizing reduced ferredoxin instead of $\mathrm{H}_{2}$ would result, in $A$. woodii, in less ATP conserved (Schuchmann and Müller, 2013). The physiological relevance of the ferredoxin entry site of the HDCR has, however, not been studied yet.

The complete reversibility of the HDCR, as opposed to membrane bound FHL complexes, is a direct reflection of its physiological function. Besides $\mathrm{H}_{2}+\mathrm{CO}_{2}, A$. woodii can grow 
for example with formate or methanol as sole carbon and energy sources (Schuchmann and Müller, 2016; Kremp et al., 2018). To convert these compounds, part of the substrate must be oxidized to $\mathrm{CO}_{2}$ to provide reducing equivalents. In these scenarios, the HDCR must operate in reverse to oxidize formate to $\mathrm{H}_{2}+\mathrm{CO}_{2}$ since it is the only formate dehydrogenase found in A. woodii (Poehlein et al., 2012)

$\mathrm{H}_{2}$ and formate are widely used electron carriers in anoxic ecosystems and are product or substrate of many microorganisms. The discovery of the HDCR enzyme as soluble, not energetically coupled enzyme complex that connects these two pools raised the question of the distribution of similar enzymes in other organisms. When searching for gene clusters containing homologs of $f d h F 1, h y c B 1 / 3$ and hydA2 of $A$. woodii we found 18 organisms encoding gene clusters encoding putative HDCRs (Figure 7), see also Schwarz et al. (2018). Of these putative enzymes only one from the acetogen Thermoanaerobacter kivui has been isolated and characterized (Schwarz et al., 2018). Of the 18 organisms, three are acetogenic bacteria that can grow with $\mathrm{H}_{2}+\mathrm{CO}_{2}$ as substrates [Clostridium difficile (Köpke et al., 2013), T. primitia (Graber and Breznak, 2004), T. kivui (Leigh et al., 1981)] and 5 belong to the sulfate reducers [Desulfotalea psychrophila (Knoblauch et al., 1999), Desulfobacterium autotrophicum (Brysch et al., 1987), Desulfovibrio alaskensis (Feio et al., 2004), Desulfovibrio magneticus (Sakaguchi et al., 2002), Desulfovibrio salexigens (Postgate and Campbell, 1966)]. In these organisms the HDCRs could play a role in the WLP as in $A$. woodii to reduce $\mathrm{CO}_{2}$ to formate either for carbon fixation alone (sulfate reducers) or for carbon fixation and energy conservation (acetogens). Many organisms from the genus Paenibacillus have putative HDCR gene clusters. Paenibacilli are found in many environments from polar to tropic regions, often found in soil where they have been reported to be associated with plant roots promoting plant growth, some species are pathogenic to honeybees or invertebrates and some are opportunistic pathogenic to humans (Grady et al., 2016). Species such as Paenibacillus polymyxa are facultative anaerobes and can ferment glucose under anoxic conditions by mixed acid fermentation to a mixture of products such as acetate, ethanol, lactate, formate, $\mathrm{H}_{2}$ and $\mathrm{CO}_{2}$ (Marwoto et al., 2004). Cell free extracts of $P$. polymyxa have been shown to contain hydrogenase activity and catalyze $\mathrm{H}_{2}$ evolution from formate (Grau and Wilson, 1962). We conclude, that in Paenibacilli the HDCR could take over the function of the FHL complex as used by $E$. coli to detoxify formate produced during fermentation by oxidizing it to $\mathrm{H}_{2}+\mathrm{CO}_{2}$.

We identified two gene clusters that show notable differences to the standard HDCR gene cluster. In this case, the hydrogenase subunit resembles the hydrogenase subunit of electron bifurcating hydrogenases by containing two additional iron-sulfur clusters. The formate dehydrogenase subunit also contains three putative additional iron-sulfur clusters whereas genes for the Hyc proteins are missing (Figure 7). The additional iron-sulfur clusters in the Hyd and Fdh subunit could take over the function of electron transfer otherwise catalyzed by the Hyc proteins. In contrast, in five other organisms we identified putative HDCR gene cluster that are more complex than the "standard" HDCR and that have, in the case of Clostridium autoethanogenum, been shown to combine features of HDCRlike enzyme complexes and electron bifurcating hydrogenases (Wang et al., 2013a).

\section{RAISING THE COMPLEXITY: FORMATE DEHYDROGENASE COUPLED ELECTRON BIFURCATING HYDROGENASES}

In the acetogenic bacterium $C$. autoethanogenum a very complex enzyme has been isolated that indeed combines the features of the HDCR enzyme complex and hydrogenases utilizing FBEB (Wang et al., 2013a). This complex is encoded by seven genes found in one cluster on the chromosome. It putatively contains 19 iron-sulfur clusters that could connect the active site of a [FeFe] hydrogenase and a selenocysteine containing bis-PGD containing formate dehydrogenase (Figure 8). In addition, a flavin is predicted to be bound to the complex. Chemical analysis of the isolated complex confirmed the presence of FMN, selenium, tungsten and $60 \mathrm{~mol}$ iron of 76 predicted mol iron per complex. Molybdenum and FAD were not detected. The enzyme complex showed very interesting catalytic properties. When incubated with $\mathrm{H}_{2}+\mathrm{CO}_{2}$ it catalyzed formate formation with $41 \mathrm{U} \mathrm{mg}^{-1}$ and the reverse reaction, $\mathrm{H}_{2}$ formation from formate with $40 \mathrm{U} \mathrm{mg}^{-1}$ thus showing the typical reversible reaction of HDCR enzymes. However, when incubated with $\mathrm{H}_{2}$, $\mathrm{NADP}^{+}$, and oxidized ferredoxin the enzyme oxidized $\mathrm{H}_{2}$ and reduced $\mathrm{NADP}^{+}$and ferredoxin simultaneously (32 $\mathrm{U} \mathrm{mg}^{-1}$ ). $\mathrm{NADP}^{+}, \mathrm{NAD}^{+}$or ferredoxin alone in the presence of $\mathrm{H}_{2}$ are not reduced. $\mathrm{H}_{2}$ could also be formed only in the presence of NADPH and reduced ferredoxin together $\left(27 \mathrm{U} \mathrm{mg}^{-1}\right)$. In addition, $\mathrm{NADP}^{+}$and oxidized ferredoxin could also be reduced with formate, again only in the presence of both electron acceptors $\left(15 \mathrm{U} \mathrm{mg}^{-1}\right)$. The same was true for the reverse reaction, $\mathrm{CO}_{2}$ reduction with NADPH and reduced ferredoxin (7 $\mathrm{U} \mathrm{mg}^{-1}$ ). It has been further demonstrated that the electron-bifurcating reactions with two electron acceptors are strictly energetically coupled (Wang et al., 2013a). Taking these results together, the enzyme represents a combination of formate dehydrogenase coupled hydrogenase as in the case of the HDCR and subunits facilitating FBEB. Interestingly, electron bifurcation to $\mathrm{NADP}^{+}$ and oxidized ferredoxin is catalyzed with two alternative electron donors, $\mathrm{H}_{2}$ or formate. Puzzling as well is the observation that $\mathrm{CO}$ inhibits not only the hydrogenase activity but also reduction of $\mathrm{NADP}^{+}$and ferredoxin with formate, even though $\mathrm{CO}$ is not known to inhibit formate dehydrogenases. The physiological function is complex as well. The enzyme is highly produced in cells grown with syngas as substrate $\left(42 \% \mathrm{CO}, 36 \% \mathrm{~N}_{2}, 20 \%\right.$ $\mathrm{CO}_{2}$, and $2 \% \mathrm{H}_{2}$ ) even though already $\mathrm{CO}$ concentrations of around $0.1 \%$ inhibit most activities of the enzyme complex to $50 \%$. Wang et al. (2013a) propose that during balanced growth on $\mathrm{CO}$ the steady state concentration within the cell is much lower than external CO concentrations thus not inhibiting the enzyme completely. The authors propose the enzyme utilizes NADPH 

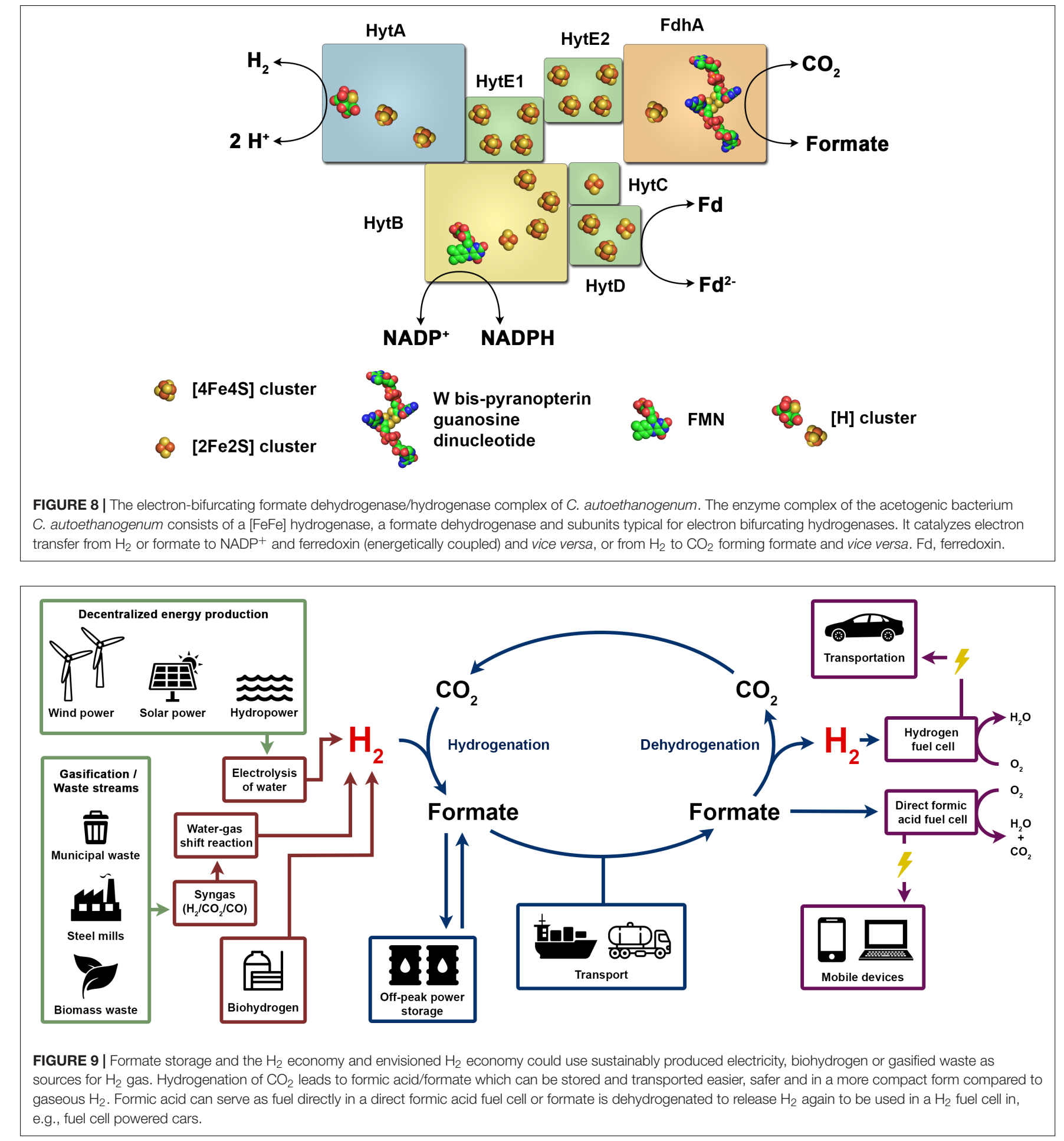

and reduced ferredoxin for $\mathrm{CO}_{2}$ reduction when cells grown on $\mathrm{CO}$ and the hydrogenase module has the function to protect the cells from over-reduction when $\mathrm{NADP}^{+}$and ferredoxin get too reduced during growth of $C$. autoethanogenum on CO. For a detailed discussion of this function we refer the reader to the original work of Wang et al. (2013a) since it is beyond the scope of this review.
In four other organisms, we identified gene clusters that encode for putative enzyme complexes resembling the electronbifurcating formate dehydrogenase/hydrogenase complex of C. autoethanogenum. These include the acetogen Clostridium carboxidivorans that can, as C. autoethanogenum utilize CO as carbon and energy source (Liou et al., 2005) and the amino acid fermenting bacteria Cloacibacillus porcorum (Looft 
et al., 2013) and Peptoclostridium acidaminophilum (formerly Eubacterium acidaminophilum) (Zindel et al., 1988) (Figure 7). $P$. acidaminophilum uses formate as electron donor to reduce glycine, sarcosine, or betaine to acetyl phosphate (Hormann and Andreesen, 1989; Andreesen, 1994). In addition, it is able to grow in syntrophic culture on, e.g., alanine, valine, leucine or malate if a hydrogen- or formate-consuming bacterium is also present (Zindel et al., 1988). The genome encodes for two putative formate dehydrogenases of which one has been isolated and characterized (Graentzdoerffer et al., 2003). The purified enzyme contained the subunits FdhF (selenocysteine and tungsten bisPGD cofactor containing formate dehydrogenase), two ironsulfur cluster containing subunits and the flavin- and $\mathrm{NAD}(\mathrm{P})$ binding subunit HydB. The corresponding gene cluster encodes for a $[\mathrm{FeFe}]$ hydrogenase, however, hydrogenase activity was lost during purification and a hydrogenase subunit or hydrogenase activity could not be detected in the isolated enzyme. On the other hand, formate dehydrogenase activity was present and showed reversible catalysis of formate oxidation $/ \mathrm{CO}_{2}$ reduction $(43 \mathrm{U}$ $\mathrm{mg}^{-1} / 12 \mathrm{U} \mathrm{mg}^{-1}$, methyl viologen as electron donor/acceptor).

\section{BIOTECHNOLOGICAL $\mathrm{H}_{2}$ PRODUCTION AND STORAGE}

$\mathrm{H}_{2}$ has been considered for a long time to replace fossil fuels in the future to tackle the climate problem by decreasing emission of $\mathrm{CO}_{2}$ (Ball and Wietschel, 2010). $\mathrm{H}_{2}$ is a very simple molecule that can be produced by various methods including splitting of water that, if the energy is provided by renewable energy sources like solar or wind power does not lead to $\mathrm{CO}_{2}$ emission. Consumption of $\mathrm{H}_{2}$ for energy generation either by thermal combustion or $\mathrm{H}_{2}$ fuel cells at the site of use does not release $\mathrm{CO}_{2}$ as well. On the other hand, significant challenges are connected with a switch to the $\mathrm{H}_{2}$ economy. Currently, $95 \%$ of world-wide $\mathrm{H}_{2}$ is produced from fossil fuels by coal gasification or by steam reforming of natural gas followed by further processing to increase the $\mathrm{H}_{2}$ yield (water-gas shift reaction) (Brandon and Kurban, 2017). These processes emit large quantities of $\mathrm{CO}_{2}$ and are not sustainable. Another major drawback of $\mathrm{H}_{2}$ is its very low density. On a gravimetric basis, the energy content of $33.3 \mathrm{kWh} / \mathrm{kg} \mathrm{H} \mathrm{H}_{2}$ is three times higher than that of gasoline. On a volumetric basis this situation is dramatically reversed to $3 \mathrm{Wh} / \mathrm{L}$ for gaseous $\mathrm{H}_{2}$ versus 8,600 $\mathrm{Wh} / \mathrm{L}$ to $9800 \mathrm{Wh} / \mathrm{L}$ for gasoline or diesel, respectively (Preuster et al., 2017a). Therefore, methods need to be developed for onboard storage of $\mathrm{H}_{2}$ in mobile applications such as cars and large-scale storage of $\mathrm{H}_{2}$, e.g., for storing energy produced by wind or solar power at off peak times. Another challenge of $\mathrm{H}_{2}$ concerns safety issues with respect to the high volatility and the formation of highly explosive gas mixtures if getting in contact with air.

A key technology to sustainably produce $\mathrm{H}_{2}$ without carbon emission is electrolysis of water driven by electricity generated from renewable sources (Ursua et al., 2012). Electrocatalytic splitting of water releases only $\mathrm{H}_{2}$ and $\mathrm{O}_{2}$ thus generating $\mathrm{H}_{2}$ free of contaminations such as $\mathrm{CO}$ which is important for $\mathrm{H}_{2}$ fuel cell applications. This process has been used already in large scale, however, the low price of fossil fuels has rendered it uneconomic. In the near future, process efficiencies of $85-95 \%$ are expected with the current price of $\mathrm{H}_{2}$ produced by electrolysis being approximately at $3 €$ per $\mathrm{kg}$ (Tremel et al., 2015).

Biological catalysis provides another alternative method for $\mathrm{H}_{2}$ production. These processes can currently not be considered as the major technology to provide $\mathrm{H}_{2}$ for the $\mathrm{H}_{2}$ economy but could provide small but significant contributions to exploit other $\mathrm{H}_{2}$ sources as well. $\mathrm{H}_{2}$ production by biological systems can be classified into four general mechanisms, namely direct and indirect biophotolysis, photofermentation, and dark fermentation which have been extensively reviewed elsewhere (Manish and Banerjee, 2008; van Niel, 2016; Kumar et al., 2018). We want to focus here on dark fermentation which has shown the highest $\mathrm{H}_{2}$ evolution rates so far (Rittmann and Herwig, 2012), biological alternatives to store $\mathrm{H}_{2}$ and the new opportunities provided by the recent discoveries of novel types of hydrogenases.

Dark fermentation can be catalyzed by single organisms or complex consortia to extract energy from multiple substrates such as waste biomass. This process has been used successfully for many years in biogas plants that convert waste biomass to methane. Within this process, $\mathrm{H}_{2}$ is produced by fermenting organisms but immediately consumed by methanogens. Selective inhibition of methanogens can stop $\mathrm{H}_{2}$ consumption leading to $\mathrm{H}_{2}$ accumulation (Schink, 1997; Catal et al., 2015). Alternatives are single organisms capable of producing large quantities of $\mathrm{H}_{2}$ either naturally or by metabolic engineering. In nature, most $\mathrm{H}_{2}$ is produced from the fermentation of carbohydrates (Thauer et al., 2008). Complete oxidation of 1 mole of hexoses such as glucose would yield a maximum of 12 moles of $\mathrm{H}_{2}$

$$
\mathrm{C}_{6} \mathrm{H}_{12} \mathrm{O}_{6}+12 \mathrm{H}_{2} \mathrm{O} \rightleftharpoons 12 \mathrm{H}_{2}+12 \mathrm{HCO}_{3}^{-}
$$

This reaction is endergonic $\left[\Delta \mathrm{G}^{0},=13.6 \mathrm{~kJ} \mathrm{~mol}^{-1}\right.$ (Flamholz et al., 2012)] and thus not feasible in vivo. The maximum $\mathrm{H}_{2}$ that can be produced from glucose by microorganisms is limited to $4 \mathrm{~mol} \mathrm{H}_{2}$ per mol of glucose known as the Thauer limit (Thauer et al., 1977). In practice, most $\mathrm{H}_{2}$ yields of microorganisms are far below this theoretical limit due to thermodynamic reasons. Oxidation of glucose to 2 pyruvate by the Embden-MeyerhofParnas pathway transfers all electrons to $\mathrm{NAD}^{+}$producing in total $2 \mathrm{NADH}$. In contrast, oxidative decarboxylation of 2 pyruvate to acetyl-CoA and $\mathrm{CO}_{2}$ can be used to reduce 2 ferredoxins as electron carrier. $\mathrm{H}_{2}$ production from ferredoxin is exergonic whereas $\mathrm{H}_{2}$ production from NADH is endergonic as described above. Thus, without a $\mathrm{H}_{2}$ consuming partner organism, $\mathrm{H}_{2}$ can only be produced from reduced ferredoxin resulting in a maximum of $2 \mathrm{H}_{2}$ produced per mol of glucose. The solution to this problem is provided by the new class of electronbifurcating hydrogenases that can produce $\mathrm{H}_{2}$ from NADH as well, driven by the coupled production of $\mathrm{H}_{2}$ from reduced ferredoxin (Buckel and Thauer, 2013). Organisms that harbor such enzymes such as T. maritima (Selig et al., 1997; Frock et al., 2012) or R. albus (Zheng et al., 2014) are able to reach the Thauer 
limit by fermenting glucose according to

$$
\text { Glucose }+2 \mathrm{H}_{2} \mathrm{O} \rightleftharpoons 4 \mathrm{H}_{2}+2 \text { Acetate }^{-}+2 \mathrm{CO}_{2}
$$

with a $\Delta \mathrm{G}^{0}$, value of $-250 \mathrm{~kJ} \mathrm{~mol}^{-1}$ at $90^{\circ} \mathrm{C}$ (growth temperature of T. maritima) and $-215 \mathrm{~kJ} \mathrm{~mol}^{-1}$ at $25^{\circ} \mathrm{C}$. An alternative strategy to reach these high $\mathrm{H}_{2}$ yields has been observed in the hyperthermophilic archaeon Pyrococcus furiosus growing at $100^{\circ} \mathrm{C}$. In this organism the $\mathrm{NAD}^{+}$-dependent glyceraldehyde-3phosphate dehydrogenase is replaced by a ferredoxin-dependent enzyme at the expense of this enzyme not being couple to ATP formation (Mukund and Adams, 1995). Thus, glucose oxidation results only in generation of reduced ferredoxin allowing full reoxidation by formation of $\mathrm{H}_{2}$.

Because of the good understanding of the metabolism and the well-established genetic tools, E. coli is the prime candidate for biotechnological applications. However, E. coli does not harbor an FBEB hydrogenase and is limited to producing $2 \mathrm{~mol} \mathrm{H}_{2}$ per mol glucose. Recently, it has been demonstrated for the first time that heterologous expression of an FBEB hydrogenase in E. coli is possible (Kelly et al., 2015). Since E. coli lacks pyruvate:ferredoxin oxidoreductase (PFO), this enzyme from T. maritima as well as ferredoxin from T. maritima had to be produced additionally in $E$. coli to achieve $\mathrm{H}_{2}$ production. The amounts and rates of $\mathrm{H}_{2}$ production were very low therefore this study can be seen as mere proof of principle that such a complex hydrogenase can be produced in E. coli, however, future studies need to prove that this approach indeed can significantly improve the $\mathrm{H}_{2}$ yields of E. coli.

The recently discovered formate dehydrogenase coupled hydrogenases could also contribute to the $\mathrm{H}_{2}$ economy in the part of $\mathrm{H}_{2}$ storage and transportation. To overcome the very low volumetric energy density of gaseous $\mathrm{H}_{2}$ many technologies are tested to store $\mathrm{H}_{2}$ in a more compact form (Schlapbach and Zuttel, 2001; Preuster et al., 2017a,b). Physical options are compression and storage in high pressure tanks above 200 bar or storage of $\mathrm{H}_{2}$ in its liquid form present at $-253^{\circ} \mathrm{C}$, both technologies requiring high energy input reducing the efficiency of $\mathrm{H}_{2}$ as energy carrier. A chemical alternative is reacting $\mathrm{H}_{2}$ with other compounds to produce liquid organic $\mathrm{H}_{2}$ carriers (LOHCs). For example, hydrogenation of $\mathrm{CO}_{2}$ leads to formic acid that contains $4.4 \mathrm{wt} \%$ of $\mathrm{H}_{2}$. This is close to the $2017 \mathrm{H}_{2}$ storage target of $5.5 \mathrm{wt}$ $\%$ in gravimetric energy density set by the United States Department of Energy at temperatures from -40 to $60^{\circ} \mathrm{C}$ at a maximum pressure of $100 \mathrm{~atm}$ (Enthaler et al., 2010; Laurenczy, 2011; Kawanami et al., 2017). The volumetric capacity is $53 \mathrm{~g} \mathrm{H}_{2} / \mathrm{L}$ formic acid thus one liter formic acid can store roughly 600 liter of gaseous $\mathrm{H}_{2}$. Formic acid is nontoxic and non-explosive, however, its corrosive nature requires special consideration for tanks and equipment. Formic acid can be decomposed to $\mathrm{H}_{2}+\mathrm{CO}_{2}$ before $\mathrm{H}_{2}$ is then used in a $\mathrm{H}_{2}$ fuel cell. Chemical catalysts have been developed that catalyze this dehydrogenation with high activity and stability at ambient temperatures below $100^{\circ} \mathrm{C}$ (Boddien et al., 2008, 2009). However, the initial hydrogenation of $\mathrm{CO}_{2}$ still represents a challenge. Many homogenous and heterogenous chemical catalyst have been developed but are depending on either high temperatures and pressures, expensive bases or special media for high efficiencies (Hull et al., 2012; Jeletic et al., 2013; Wang et al., 2015; Eppinger and Huang, 2017). Highest rates for $\mathrm{CO}_{2}$ hydrogenation (TOF 3,400 $\mathrm{h}^{-1}$ ) with chemical catalyst at ambient conditions have been achieved with cobalt based catalysts in the presence of a special and expensive base (Verkade's base) (Jeletic et al., 2013). The newly discovered HDCR complexes could provide a biotechnological alternative or could serve as model to design more efficient catalysts. HDCR of $A$. woodii catalyzes $\mathrm{CO}_{2}$ hydrogenation with a TOF of $101,600 \mathrm{~h}^{-1}$ at $30^{\circ} \mathrm{C}$ and 1 bar of pressure (Schuchmann and Müller, 2013). In contrast to other $\mathrm{CO}_{2}$ reductases the enzyme directly utilizes $\mathrm{H}_{2}$ thus not requiring soluble electron carriers. In addition, with even higher TOFs it catalyzes the reverse reaction as well, closing the cycle for a $\mathrm{H}_{2}$ storage process. By coupling the HDCR with a ferredoxin dependent $\mathrm{CO}$ dehydrogenase, conversion of syngas $\left(\mathrm{H}_{2}, \mathrm{CO}\right.$, $\mathrm{CO}_{2}$ ) or $\mathrm{CO}$ alone to formate was achieved (Schuchmann and Müller, 2013). This is advantageous since CO is very toxic to $\mathrm{H}_{2}$ fuel cells and can be removed by intermittent conversion of the gases to formate. Major drawbacks are the high oxygen sensitivity and inherent stability issues typical for biocatalysts such as narrow $\mathrm{pH}$ and temperature range. To overcome the requirement of enzyme isolation, a whole cell system has been established using $A$. woodii as catalyst for reversible $\mathrm{H}_{2}$ storage (Schuchmann and Müller, 2013). Genetic manipulations were not required since competing pathways for product formation were inhibited by addition of a sodium ionophore that makes the cytoplasmic membrane permeable for sodium ions thus inhibiting energy conservation and ATP synthesis. Using this system, formate could be specifically produced from $\mathrm{H}_{2}+\mathrm{CO}_{2}$ reaching final concentrations (up to $\sim 0.25 \mathrm{M}$ formate) that where only limited by the thermodynamics of the reaction. Formate was produced with a rate of $120 \mathrm{mmol}$ formate $\mathrm{h}^{-1} \mathrm{~g}^{-1}$. Formate decomposition was catalyzed by whole cells with activities up to $71 \mathrm{mmol}$ $\mathrm{H}_{2} \mathrm{~h}^{-1} \mathrm{~g}^{-1}$ (Kottenhahn et al., 2018). Yields of $1 \mathrm{~mol} \mathrm{H}_{2}$ per mol of formate were demonstrated. Recently, the first HDCR from a thermophile, namely the acetogen T. kivui, was isolated (Schwarz et al., 2018). This enzyme showed surprising activities with TOFs for $\mathrm{CO}_{2}$ hydrogenation of $9,556,000 \mathrm{~h}^{-1}$ at $60^{\circ} \mathrm{C}$ and still $1,856,000 \mathrm{~h}^{-1}$ at $30^{\circ} \mathrm{C}$. Formate dehydrogenation was catalyzed with a TOF of $9,892,000 \mathrm{~h}^{-1}$. This enzyme contained in contrast to the HDCR of $A$. woodii tungsten instead of molybdenum and no selenocysteine in the formate dehydrogenase subunit. Future insights into the structure and biochemistry of this enzyme will hopefully unravel the factors determining this tremendous $\mathrm{CO}_{2}$ reductase activities not observed for other apparently very similar formate dehydrogenases.

One alternative for HDCR catalysis of $\mathrm{CO}_{2}$ hydrogenation is the FHL enzyme complex as found in E. coli. For many years thought to work efficiently only in direction of formate oxidation, recent work has demonstrated the reversibility. Even though $\mathrm{CO}_{2}$ reductase activity of the isolated enzyme are orders 
of magnitude slower compared to HDCR enzymes, whole cell catalysis under high pressure showed promising results (Roger et al., 2018). Utilizing a genetically modified strain that is deficient in competing formate dehydrogenases, hydrogenases and pyruvate formate lyase that are otherwise present in E. coli and using 10 bar of $\mathrm{H}_{2}+\mathrm{CO}_{2}\left(\mathrm{H}_{2}: \mathrm{CO}_{2}\right.$ ratio $\left.1: 1\right)$ at $37^{\circ} \mathrm{C}$ approximately $500 \mathrm{mM}$ formate could be produced over a time course of $23 \mathrm{~h}$. Yields reached 100\% (produced formate per consumed $\mathrm{CO}_{2}$ ) and initial rates of $36 \mathrm{mmol}$ formate produced $\mathrm{h}^{-1} \mathrm{~g}^{-1}$ were demonstrated. Even though the FHL enzyme has less advantageous catalytic properties in the isolated form and has the disadvantage of being a membrane integral enzyme complex, the catalytic rates observed with whole cells of $E$. coli in the highpressure system are in the same order of magnitude as whole cell catalysis with $A$. woodii, however, the latter being performed at ambient pressures.

How could formic acid be integrated in the $\mathrm{H}_{2}$ economy? As shown in Figure 9, energy production from renewable sources such as solar or wind power will be more decentralized. Electricity produced could be converted electrochemically by water splitting into $\mathrm{H}_{2}$. Alternative $\mathrm{H}_{2}$ sources can be biohydrogen produced for example from waste biomass and multiple sources of synthesis gas such as industrial off-gas or gasification of municipal waste or biomass. $\mathrm{H}_{2}$ production from syngas are well established technologies utilized already as major pathway for $\mathrm{H}_{2}$ production. In the next step, $\mathrm{H}_{2}$ could be bound to $\mathrm{CO}_{2}$ at decentralized facilities producing formic acid that could then be stored in bulk amounts for energy storage or distributed to the final customer. Formic acid could be used directly for energy generation in direct formic acid fuel cells (DFAFCs) that are potential power sources for portable devices (Aslama et al., 2012). DFAFCs are less well developed compared to $\mathrm{H}_{2}$ fuel cells. Therefore, for utilization in $\mathrm{H}_{2}$ fuel cells, $\mathrm{H}_{2}$ must be generated first by dehydrogenation of formic acid again at the site of use. Combustion of formic acid directly or $\mathrm{H}_{2}$ after formic acid dehydrogenation results in release of water and $\mathrm{CO}_{2}$ only. $\mathrm{CO}_{2}$ can be used for the next $\mathrm{H}_{2}$ storage cycle; therefore, no net $\mathrm{CO}_{2}$ is generated.

\section{CONCLUSION}

Enzymes utilizing $\mathrm{H}_{2}$ are known for almost a century and since the first crystal structure of a hydrogenase in 1995 (Volbeda et al., 1995) a very large number of studies revealed many facets of the biochemistry, reaction mechanism and evolution of hydrogenases. Most knowledge has been gained about the core subunit of hydrogenases that harbors the active site for $\mathrm{H}_{2}$ oxidation/ $\mathrm{H}^{+}$reduction, however, in recent

\section{REFERENCES}

Andreesen, J. R. (1994). "Glycine metabolism in anaerobes," in Acetogenesis, ed. H. L. Drake (New York, NY: Chapman and Hall), 568-629. doi: 10.1007/978-14615-1777-1_23

Appel, A. M., Bercaw, J. E., Bocarsly, A. B., Dobbek, H., DuBois, D. L., Dupuis, M., et al. (2013). Frontiers, opportunities, and challenges in biochemical and years more and more hydrogenases have been discovered that are part of large and very complex multimeric enzymes connecting $\mathrm{H}_{2}$ oxidation to multiple functions. One of the major breakthroughs in (anaerobic) microbiology within the last decade was the discovery of the novel enzyme mechanisms of FBEB. This discovery solved many thermodynamic enigmas within the physiology of anaerobic microorganisms. Concerning $\mathrm{H}_{2}$ production, unraveling of hydrogenases utilizing FBEB finally solved the long-standing questions how $\mathrm{H}_{2}$ production from $\mathrm{NADH}$ is possible and, the other way around, how $\mathrm{H}_{2}$ can be used to reduce ferredoxin, both highly endergonic reactions without energetic coupling to other redox reactions. These enzymes follow a modular architecture with the large subunit of [ $\mathrm{FeFe}]$ hydrogenases HydA being coupled to other functional subunits. The same is true for hydrogenases coupled to formate dehydrogenases or the combination of hydrogenase, formate dehydrogenase and electron bifurcation. All these enzymes contain a large number of iron-sulfur clusters that are supposed to accomplish the electrical connection of the different active sites or the active sites and multiple electron acceptors. The biochemical characterization of all these enzymes needs now to be followed by detail insights into the structure and reaction mechanisms. FBEB hydrogenases constitute a fascinating puzzle on how the splitting and energetic coupling of the two electrons is achieved since the flavin to take over this function in other characterized FBEB enzymes is apparently missing. The idea that indeed a metal center can take over this function is a compelling thought. On the other hand, a detailed understanding of $\mathrm{H}_{2}-$ dependent $\mathrm{CO}_{2}$ reductases would not only be important from a biochemical point of view but could also help to provide better catalysts for economic problems such as $\mathrm{H}_{2}$ storage. After more than two decades focusing on the major subunit of hydrogenases the next decade might reveal the fascinating complexity of the auxiliary subunits of this still highly important class of enzymes.

\section{AUTHOR CONTRIBUTIONS}

All authors listed have made a substantial, direct and intellectual contribution to the work, and approved it for publication.

\section{FUNDING}

Work from the authors laboratory was funded by the Deutsche Forschungsgemeinschaft and the European Research Council (ERC) under the European Union's Horizon 2020 Research and Innovation Programme (Grant Agreement No. 741791).

chemical catalysis of $\mathrm{CO}_{2}$ fixation. Chem. Rev. 113, 6621-6658. doi: 10.1021/ cr300463y

Aslama, N. M., Masdara, M. S., Kamarudina, S. K., and Dauda, W. R. W. (2012). Overview on direct formic acid fuel cells (DFAFCs) as an energy sources. APCBEE Procedia 3, 33-39. doi: 10.1016/j.apcbee.2012.06.042

Axley, M. J., Bock, A., and Stadtman, T. C. (1991). Catalytic properties of an Escherichia coli formate dehydrogenase mutant in which sulfur replaces 
selenium. Proc. Natl. Acad. Sci. U.S.A. 88, 8450-8454. doi: 10.1073/pnas.88.19. 8450

Axley, M. J., Grahame, D. A., and Stadtman, T. C. (1990). Escherichia coli formatehydrogen lyase - purification and properties of the selenium-dependent formate dehydrogenase component. J. Biol. Chem. 265, 18213-18218.

Baffert, C., Bertini, L., Lautier, T., Greco, C., Sybirna, K., Ezanno, P., et al. (2011). $\mathrm{CO}$ disrupts the reduced $\mathrm{H}$-cluster of $\mathrm{FeFe}$ hydrogenase. A combined DFT and protein film voltammetry study. J. Am. Chem. Soc. 133, 2096-2099. doi: $10.1021 /$ ja110627b

Bagramyan, K. A., and Martirosov, S. M. (1989). Formation of an ion transport supercomplex in Escherichia coli. An experimental model of direct transduction of energy. FEBS Lett. 246, 149-152. doi: 10.1016/0014-5793(89)80 $272-8$

Ball, M., and Wietschel, M. (2010). The Hydrogen Economy: Opportunities and Challenges. Cambridge: Cambridge University Press.

Bassegoda, A., Madden, C., Wakerley, D. W., Reisner, E., and Hirst, J. (2014). Reversible interconversion of $\mathrm{CO}_{2}$ and formate by a molybdenum-containing formate dehydrogenase. J. Am. Chem. Soc. 136, 15473-15476. doi: 10.1021/ ja508647u

Baymann, F., Schoepp-Cothenet, B., Duval, S., Guiral, M., Brugna, M., Baffert, C., et al. (2018). On the natural history of flavin-based electron bifurcation. Front. Microbiol. 9:1357. doi: 10.3389/fmicb.2018.01357

Beller, M., and Bornscheuer, U. T. (2014). $\mathrm{CO}_{2}$ fixation through hydrogenation by chemical or enzymatic methods. Angew. Chem. Int. Ed. Engl. 53, 4527-4528. doi: 10.1002/anie.201402963

Bengelsdorf, F. R., Poehlein, A., Linder, S., Erz, C., Hummel, T., Hoffmeister, S., et al. (2016). Industrial acetogenic biocatalysts: a comparative metabolic and genomic analysis. Front. Microbiol. 7:1036. doi: 10.3389/fmicb.2016.01036

Bennett, B. D., Kimball, E. H., Gao, M., Osterhout, R., Van Dien, S. J., and Rabinowitz, J. D. (2009). Absolute metabolite concentrations and implied enzyme active site occupancy in Escherichia coli. Nat. Chem. Biol. 5, 593-599. doi: $10.1038 /$ nchembio. 186

Bertsch, J., and Müller, V. (2015a). Bioenergetic constraints for conversion of syngas to biofuels in acetogenic bacteria. Biotechnol. Biofuels 8, 1-12. doi: 10. 1186/s13068-015-0393-x

Bertsch, J., and Müller, V. (2015b). CO metabolism in the acetogen Acetobacterium woodii. Appl. Environ. Microbiol. 81, 5949-5956. doi: 10.1128/AEM.01772-15

Bertsch, J., Parthasarathy, A., Buckel, W., and Müller, V. (2013). An electronbifurcating caffeyl-CoA reductase. J. Biol. Chem. 288, 11304-11311. doi: 10. 1074/jbc.M112.444919

Bertsch, J., Siemund, A. L., Kremp, F., and Muller, V. (2015). A novel route for ethanol oxidation in the acetogenic bacterium Acetobacterium woodii: the AdhE pathway. Environ. Microbiol. 18, 2913-2922. doi: 10.1111/1462-2920.13082

Biegel, E., and Müller, V. (2010). Bacterial $\mathrm{Na}^{+}$-translocating ferredoxin: $\mathrm{NAD}^{+}$ oxidoreductase. Proc. Natl. Acad. Sci. U.S.A. 107, 18138-18142. doi: 10.1073/ pnas. 1010318107

Biegel, E., and Müller, V. (2011). A Na ${ }^{+}$-translocating pyrophosphatase in the acetogenic bacterium Acetobacterium woodii. J. Biol. Chem. 286, 6080-6084. doi: 10.1074/jbc.M110.192823

Biegel, E., Schmidt, S., González, J. M., and Müller, V. (2011). Biochemistry, evolution and physiological function of the Rnf complex, a novel ion-motive electron transport complex in prokaryotes. Cell. Mol. Life Sci. 68, 613-634. doi: $10.1007 / \mathrm{s} 00018-010-0555-8$

Blamey, J. M., and Adams, M. W. (1993). Purification and characterization of pyruvate ferredoxin oxidoreductase from the hyperthermophilic archaeon Pyrococcus furiosus. Biochim. Biophys. Acta 1161, 19-27. doi: 10.1016/01674838(93)90190-3

Böck, A., Thanbichler, M., Rother, M., and Resch, A. (2005). "Selenocysteine," in The Aminoacyl-tRNA Synthetases, eds M. Ibba, C. Fancklyn, and S. Cusack (Georgetown: Landes Bioscience), 320-327.

Boddien, A., Loges, B., Junge, H., and Beller, M. (2008). Hydrogen generation at ambient conditions: application in fuel cells. ChemSusChem 1, 751-758. doi: $10.1002 /$ cssc. 200800093

Boddien, A., Loges, B., Junge, H., Gartner, F., Noyes, J. R., and Beller, M. (2009). Continuous hydrogen generation from formic acid: highly active and stable ruthenium catalysts. Adv. Synth. Catal. 351, 2517-2520. doi: 10.1002/adsc. 200900431
Böhm, R., Sauter, M., and Böck, A. (1990). Nucleotide sequence and expression of an operon in Escherichia coli coding for formate hydrogen lyase components. Mol. Microbiol. 4, 231-243. doi: 10.1111/j.1365-2958.1990.tb00590.x

Boyington, J. C., Gladyshev, V. N., Khangulov, S. V., Stadtman, T. C., and Sun, P. D. (1997). Crystal structure of formate dehydrogenase H: catalysis involving Mo, molybdopterin, selenocysteine, and an Fe4S4 cluster. Science 275, 1305-1308. doi: 10.1126/science.275.5304.1305

Brandon, N. P., and Kurban, Z. (2017). Clean energy and the hydrogen economy. Philos. Trans. R. Soc. A 375:20160400. doi: 10.1098/rsta.2016.0400

Brysch, K., Schneider, C., Fuchs, G., and Widdel, F. (1987). Lithoautotrophic growth of sulfate-reducing bacteria, and description of Desulfobacterium autotrophicum gen. nov., sp. nov. Arch. Microbiol. 148, 264-274. doi: 10.1007/ BF00456703

Buckel, W., and Thauer, R. K. (2013). Energy conservation via electron bifurcating ferredoxin reduction and proton/ $\mathrm{Na}^{+}$translocating ferredoxin oxidation. Biochim. Biophys. Acta 1827, 94-113. doi: 10.1016/j.bbabio.2012.07.002

Buckel, W., and Thauer, R. K. (2018a). Flavin-based electron bifurcation, a new mechanism of biological energy coupling. Chem. Rev. 118, 3862-3886. doi: 10.1021/acs.chemrev.7b00707

Buckel, W., and Thauer, R. K. (2018b). Flavin-based electron bifurcation, ferredoxin, flavodoxin, and anaerobic respiration with protons (Ech) or $\mathrm{NAD}^{+}$ (Rnf) as electron acceptors: a historical review. Front. Microbiol. 9:401. doi: 10.3389/fmicb.2018.00401

Bulushev, D. A., and Ross, J. R. H. (2018). Towards sustainable production of formic acid. Chemsuschem 11, 821-836. doi: 10.1002/cssc.201702075

Calusinska, M., Happe, T., Joris, B., and Wilmotte, A. (2010). The surprising diversity of clostridial hydrogenases: a comparative genomic perspective. Microbiology 156, 1575-1588. doi: 10.1099/mic.0.032771-0

Catal, T., Lesnik, K. L., and Liu, H. (2015). Suppression of methanogenesis for hydrogen production in single chamber microbial electrolysis cells using various antibiotics. Bioresour. Technol. 187, 77-83. doi: 10.1016/j.biortech.2015. 03.099

Ceccaldi, P., Schuchmann, K., Müller, V., and Elliott, S. J. (2017). The hydrogen dependent $\mathrm{CO}_{2}$ reductase: the first completely $\mathrm{CO}$ tolerant FeFe-hydrogenase. Energy. Environm. Sci. 10, 503-508. doi: 10.1039/C6EE02494G

Chang, C. H., King, P. W., Ghirardi, M. L., and Kim, K. (2007). Atomic resolution modeling of the ferredoxin:[FeFe] hydrogenase complex from Chlamydomonas reinhardtii. Biophys. J. 93, 3034-3045. doi: 10.1529/biophysj.107.108589

Chowdhury, N. P., Kahnt, J., and Buckel, W. (2015). Reduction of ferredoxin or oxygen by flavin-based electron bifurcation in Megasphaera elsdenii. FEBS J. 282, 3149-3160. doi: 10.1111/febs.13308

Chowdhury, N. P., Klomann, K., Seubert, A., and Buckel, W. (2016). Reduction of flavodoxin by electron bifurcation and sodium ion-dependent reoxidation by $\mathrm{NAD}^{+}$catalyzed by ferredoxin-NAD ${ }^{+}$reductase (Rnf). J. Biol. Chem. 291, 11993-12002. doi: 10.1074/jbc.M116.726299

Chowdhury, N. P., Mowafy, A. M., Demmer, J. K., Upadhyay, V., Koelzer, S., Jayamani, E., et al. (2014). Studies on the mechanism of electron bifurcation catalyzed by electron transferring flavoprotein (Etf) and butyryl-CoA dehydrogenase (Bcd) of Acidaminococcus fermentans. J. Biol. Chem. 289, 51455157. doi: 10.1074/jbc.M113.521013

Clark, D. P. (1989). The fermentation pathways of Escherichia coli. FEMS Microbiol. Rev. 5, 223-234. doi: 10.1016/0168-6445(89)90033-8

Conrad, R., Schink, B., and Phelps, T. J. (1986). Thermodynamics of $\mathrm{H}_{2}$-consuming and $\mathrm{H}_{2}$-producing metabolic reactions in diverse methanogenic environments under in situ conditions. FEMS Microbiol. Ecol. 38, 353-360. doi: 10.1111/j. 1574-6968.1986.tb01748.x

Crable, B. R., Plugge, C. M., McInerney, M. J., and Stams, A. J. (2011). Formate formation and formate conversion in biological fuels production. Enzyme Res. 2011:532536. doi: 10.4061/2011/532536

de Bok, F. A., Hagedoorn, P. L., Silva, P. J., Hagen, W. R., Schiltz, E., Fritsche, K., et al. (2003). Two $\mathrm{W}$-containing formate dehydrogenases $\left(\mathrm{CO}_{2}\right.$-reductases) involved in syntrophic propionate oxidation by Syntrophobacter fumaroxidans. Eur. J. Biochem. 270, 2476-2485. doi: 10.1046/j.1432-1033.2003.03619.x

Demmer, J. K., Huang, H., Wang, S., Demmer, U., Thauer, R. K., and Ermler, U. (2015). Insights into flavin-based electron bifurcation via the NADH-dependent reduced ferredoxin:NADP ${ }^{+}$oxidoreductase structure. J. Biol. Chem. 290, 21985-21995. doi: 10.1074/jbc.M115.656520 
Demmer, J. K., Pal Chowdhury, N., Selmer, T., Ermler, U., and Buckel, W. (2017). The semiquinone swing in the bifurcating electron transferring flavoprotein/butyryl-CoA dehydrogenase complex from Clostridium difficile. Nat. Commun. 8:1577. doi: 10.1038/s41467-017-01746-3

Dunn, S. (2002). Hydrogen futures: toward a sustainable energy system. Int. J. Hydrogen Energy 27, 235-264. doi: 10.1016/S0360-3199(01)00131-8

Enthaler, S., von Langermann, J., and Schmidt, T. (2010). Carbon dioxide and formic acid-the couple for environmental-friendly hydrogen storage? Energy Environ. Sci. 3, 1207-1217. doi: 10.1039/b907569k

Eppinger, J., and Huang, K. W. (2017). Formic acid as a hydrogen energy carrier. ACS Energy Lett. 2, 188-195. doi: 10.1021/acsenergylett.6b00574

Feio, M. J., Zinkevich, V., Beech, I. B., Llobet-Brossa, E., Eaton, P., Schmitt, J., et al. (2004). Desulfovibrio alaskensis sp. nov., a sulphate-reducing bacterium from a soured oil reservoir. Int. J. Syst. Evol. Microbiol. 54, 1747-1752. doi: 10.1099/ijs.0.63118-0

Flamholz, A., Noor, E., Bar-Even, A., and Milo, R. (2012). eQuilibrator-the biochemical thermodynamics calculator. Nucleic Acids Res. 40, D770-D775. doi: $10.1093 /$ nar/gkr874

Fontecilla-Camps, J. C., and Ragsdale, S. W. (1999). Nickel-iron-sulfur active sites: hydrogenase and CO dehydrogenase. Adv. Inorg. Chem. 47, 283-333. doi: 10.1016/S0898-8838(08)60081-1

Foster, C. E., Kramer, T., Wait, A. F., Parkin, A., Jennings, D. P., Happe, T., et al. (2012). Inhibition of [FeFe]-hydrogenases by formaldehyde and wider mechanistic implications for biohydrogen activation. J. Am. Chem. Soc. 134, 7553-7557. doi: 10.1021/ja302096r

Fourmond, V., Baffert, C., Sybirna, K., Dementin, S., Abou-Hamdan, A., MeynialSalles, I., et al. (2013). The mechanism of inhibition by $\mathrm{H}_{2}$ of $\mathrm{H}_{2}$-evolution by hydrogenases. Chem. Commun. 49, 6840-6842. doi: 10.1039/c3cc43297a

Fox, J. D., He, Y., Shelver, D., Roberts, G. P., and Ludden, P. W. (1996). Characterization of the region encoding the CO-induced hydrogenase of Rhodospirillum rubrum. J. Bacteriol. 178, 6200-6208. doi: 10.1128/jb.178.21. 6200-6208.1996

Friedebold, J., and Bowien, B. (1993). Physiological and biochemical characterization of the soluble formate dehydrogenase, a molybdoenzyme from Alcaligenes eutrophus. J. Bacteriol. 175, 4719-4728. doi: 10.1128/jb.175. 15.4719-4728.1993

Frock, A. D., Gray, S. R., and Kelly, R. M. (2012). Hyperthermophilic Thermotoga species differ with respect to specific carbohydrate transporters and glycoside hydrolases. Appl. Environ. Microbiol. 78, 1978-1986. doi: 10.1128/AEM.0706911

Fuchs, G. (2011). Alternative pathways of carbon dioxide fixation: insights into the early evolution of life? Annu. Rev. Microbiol. 65, 631-658. doi: 10.1146/ annurev-micro-090110-102801

Fujita, E., Muckerman, J. T., and Himeda, Y. (2013). Interconversion of $\mathrm{CO}_{2}$ and formic acid by bio-inspired Ir complexes with pendent bases. Biochim. Biophys. Acta 1827, 1031-1038. doi: 10.1016/j.bbabio.2012.11.004

Gladyshev, V. N., Boyington, J. C., Khangulov, S. V., Grahame, D. A., Stadtman, T. C., and Sun, P. D. (1996). Characterization of crystalline formate dehydrogenase H from Escherichia coli. Stabilization, EPR spectroscopy, and preliminary crystallographic analysis. J. Biol. Chem. 271, 8095-8100. doi: 10 . 1074/jbc.271.14.8095

Goldet, G., Brandmayr, C., Stripp, S. T., Happe, T., Cavazza, C., Fontecilla-Camps, J. C., et al. (2009). Electrochemical kinetic investigations of the reactions of [FeFe]-hydrogenases with carbon monoxide and oxygen: comparing the importance of gas tunnels and active-site electronic/redox effects. J. Am. Chem. Soc. 131, 14979-14989. doi: 10.1021/ja905388j

Graber, J. R., and Breznak, J. A. (2004). Physiology and nutrition of Treponema primitia, an $\mathrm{H}_{2} / \mathrm{CO}_{2}$-acetogenic spirochete from termite hindguts. Appl. Environ. Microbiol. 70, 1307-1314. doi: 10.1128/AEM.70.3.1307-1314.2004

Grady, E. N., MacDonald, J., Liu, L., Richman, A., and Yuan, Z. C. (2016). Current knowledge and perspectives of Paenibacillus: a review. Microb. Cell Fact. 15:203. doi: 10.1186/s12934-016-0603-7

Graentzdoerffer, A., Rauh, D., Pich, A., and Andreesen, J. R. (2003). Molecular and biochemical characterization of two tungsten- and seleniumcontaining formate dehydrogenases from Eubacterium acidaminophilum that are associated with components of an iron-only hydrogenase. Arch. Microbiol. 179, 116-130. doi: 10.1007/s00203-002-0508-1
Grau, F. H., and Wilson, P. W. (1962). Physiology of nitrogen fixation by Bacillus polymyxa. J. Bacteriol. $83,490-496$.

Greening, C., Berney, M., Hards, K., Cook, G. M., and Conrad, R. (2014a). A soil actinobacterium scavenges atmospheric $\mathrm{H}_{2}$ using two membrane-associated, oxygen-dependent [NiFe] hydrogenases. Proc. Natl. Acad. Sci. U.S.A. 111, 4257-4261. doi: 10.1073/pnas.1320586111

Greening, C., Constant, P., Hards, K., Morales, S., Oakeshott, J. G., Russell, R. J., et al. (2014b). Atmospheric hydrogen scavenging: from enzymes to ecosystems. Appl. Environ. Microbiol. 81, 1190-1199.

Hakobyan, B., Pinske, C., Sawers, G., Trchounian, A., and Trchounian, K. (2018). pH and a mixed carbon-substrate spectrum influence FocA- and FocBdependent, formate-driven $\mathrm{H}_{2}$ production in Escherichia coli. FEMS Microbiol. Lett. 365:fny233. doi: 10.1093/femsle/fny233

Hakobyan, M., Sargsyan, H., and Bagramyan, K. (2005). Proton translocation coupled to formate oxidation in anaerobically grown fermenting Escherichia coli. Biophys. Chem. 115, 55-61. doi: 10.1016/j.bpc.2005.01.002

Happe, R. P., Roseboom, W., Pierik, A. J., Albracht, S. P. J., and Bagley, K. A. (1997). Biological activation of hydrogen. Nature 385, 126-126. doi: 10.1038/385126a0

Herrmann, G., Jayamani, E., Mai, G., and Buckel, W. (2008). Energy conservation via electron-transferring flavoprotein in anaerobic bacteria. J. Bacteriol. 190, 784-791. doi: 10.1128/JB.01422-07

Hormann, K., and Andreesen, J. R. (1989). Reductive cleavage of sarcosine and betaine by Eubacterium acidaminophilum via enzyme systems different from glycine reductase. Arch. Microbiol. 153, 50-59. doi: 10.1007/BF00277541

Hull, J. F., Himeda, Y., Wang, W. H., Hashiguchi, B., Periana, R., Szalda, D. J., et al. (2012). Reversible hydrogen storage using $\mathrm{CO}_{2}$ and a proton-switchable iridium catalyst in aqueous media under mild temperatures and pressures. Nat. Chem. 4, 383-388. doi: 10.1038/nchem.1295

Jeletic, M. S., Mock, M. T., Appel, A. M., and Linehan, J. C. (2013). A cobalt-based catalyst for the hydrogenation of $\mathrm{CO}_{2}$ under ambient conditions. J. Am. Chem. Soc. 135, 11533-11536. doi: 10.1021/ja406601v

Kawanami, H., Himeda, Y., and Laurenczy, G. (2017). Formic acid as a hydrogen carrier for fuel cells toward a sustainable energy system. Adv. Inorg. Chem. 70, 395-427. doi: 10.1016/bs.adioch.2017.04.002

Kelly, C. L., Pinske, C., Murphy, B. J., Parkin, A., Armstrong, F., Palmer, T., et al. (2015). Integration of an [FeFe]-hydrogenase into the anaerobic metabolism of Escherichia coli. Biotechnol. Rep. 8, 94-104. doi: 10.1016/j.btre.2015.10.002

Knoblauch, C., Sahm, K., and Jorgensen, B. B. (1999). Psychrophilic sulfatereducing bacteria isolated from permanently cold arctic marine sediments: description of Desulfofrigus oceanense gen. nov., sp. nov., Desulfofrigus fragile sp. nov., Desulfofaba gelida gen. nov., sp. nov., Desulfotalea psychrophila gen. nov., sp. nov. and Desulfotalea arctica sp. nov. Int. J. Syst. Bacteriol. 49(Pt 4), 1631-1643.

Köpke, M., Straub, M., and Dürre, P. (2013). Clostridium difficile is an autotrophic bacterial pathogen. PLoS One 8:e62157. doi: 10.1371/journal.pone.0062157

Kottenhahn, P., Schuchmann, K., and Müller, V. (2018). Efficient whole cell biocatalyst for formate-based hydrogen production. Biotechnol. Biofuels. 11:93. doi: 10.1186/s13068-018-1082-3

Kremp, F., Poehlein, A., Daniel, R., and Müller, V. (2018). Methanol metabolism in the acetogenic bacterium Acetobacterium woodii. Environ. Microbiol. doi: 10.1111/1462-2920.14356 [Epub ahead of print].

Kumar, G., Shobana, S., Nagarajan, D., Lee, D. J., Lee, K. S., Lin, C. Y., et al. (2018). Biomass based hydrogen production by dark fermentation - recent trends and opportunities for greener processes. Curr. Opin. Biotechnol. 50, 136-145. doi: 10.1016/j.copbio.2017.12.024

Künkel, A., Vorholt, J. A., Thauer, R. K., and Hedderich, R. (1998). An Escherichia coli hydrogenase-3-type hydrogenase in methanogenic archaea. Eur. J. Biochem. 252, 467-476. doi: 10.1046/j.1432-1327.1998.2520467.x

Laukel, M., Chistoserdova, L., Lidstrom, M. E., and Vorholt, J. A. (2003). The tungsten-containing formate dehydrogenase from Methylobacterium extorquens AM1: purification and properties. Eur. J. Biochem. 270, 325-333. doi: 10.1046/j.1432-1033.2003.03391.x

Laurenczy, G. (2011). Hydrogen storage and delivery: the carbon dioxide - formic acid couple. Chimia 65, 663-666. doi: 10.2533/chimia.2011.663

Ledbetter, R. N., Garcia Costas, A. M., Lubner, C. E., Mulder, D. W., TokminaLukaszewska, M., Artz, J. H., et al. (2017). The electron bifurcating FixABCX protein complex from Azotobacter vinelandii: generation of low-potential 
reducing equivalents for nitrogenase catalysis. Biochemistry 56, 4177-4190. doi: 10.1021/acs.biochem.7b00389

Leigh, J. A., Mayer, F., and Wolfe, R. S. (1981). Acetogenium kivui, a new thermophilic hydrogen-oxidizing, acetogenic bacterium. Arch. Microbiol. 129, 275-280. doi: 10.1007/BF00414697

Li, F., Hinderberger, J., Seedorf, H., Zhang, J., Buckel, W., and Thauer, R. K. (2008). Coupled ferredoxin and crotonyl coenzyme A (CoA) reduction with NADH catalyzed by the butyryl-CoA dehydrogenase/Etf complex from Clostridium kluyveri. J. Bacteriol. 190, 843-850. doi: 10.1128/JB.01417-07

Liou, J. S., Balkwill, D. L., Drake, G. R., and Tanner, R. S. (2005). Clostridium carboxidivorans sp. nov., a solvent-producing clostridium isolated from an agricultural settling lagoon, and reclassification of the acetogen Clostridium scatologenes strain SL1 as Clostridium drakei sp. nov. Int. J. Syst. Evol. Microbiol. 55, 2085-2091. doi: 10.1099/ijs.0.63482-0

Looft, T., Levine, U. Y., and Stanton, T. B. (2013). Cloacibacillus porcorum sp. nov., a mucin-degrading bacterium from the swine intestinal tract and emended description of the genus Cloacibacillus. Int. J. Syst. Evol. Microbiol. 63, 19601966. doi: 10.1099/ijs.0.044719-0

Losey, N. A., Mus, F., Peters, J. W., Le, H. M., and McInerney, M. J. (2017). Syntrophomonas wolfei uses an NADH-dependent, ferredoxin-independent [FeFe]-hydrogenase to reoxidize NADH. Appl. Environ. Microbiol. 83. doi: 10. 1128/AEM.01335-17

Lu, W., Du, J., Wacker, T., Gerbig-Smentek, E., Andrade, S. L., and Einsle, O. (2011). pH-dependent gating in a FocA formate channel. Science 332, 352-354. doi: 10.1126/science.1199098

Lubitz, W., Ogata, H., Rüdiger, O., and Reijerse, E. (2014). Hydrogenases. Chem. Rev. 114, 4081-4148. doi: 10.1021/cr4005814

Lubner, C. E., Jennings, D. P., Mulder, D. W., Schut, G. J., Zadvornyy, O. A., Hoben, J. P., et al. (2017). Mechanistic insights into energy conservation by flavin-based electron bifurcation. Nat. Chem. Biol. 13, 655-659. doi: 10.1038/nchembio.2348

Manish, S., and Banerjee, R. (2008). Comparison of biohydrogen production processes. Int. J. Hydrogen Energy 33, 279-286. doi: 10.1016/j.ijhydene.2007. 07.026

Marwoto, B., Nakashimada, Y., Kakizono, T., and Nishio, N. (2004). Metabolic analysis of acetate accumulation during xylose consumption by Paenibacillus polymyxa. Appl. Microbiol. Biotechnol. 64, 112-119. doi: 10.1007/s00253-0031435-z

Matson, E. G., Zhang, X., and Leadbetter, J. R. (2010). Selenium controls transcription of paralogous formate dehydrogenase genes in the termite gut acetogen, Treponema primitia. Environ. Microbiol. Rep. 12, 2245-2258. doi: $10.1111 /$ j.1462-2920.2010.02188.x

McDowall, J. S., Murphy, B. J., Haumann, M., Palmer, T., Armstrong, F. A., and Sargent, F. (2014). Bacterial formate hydrogenlyase complex. Proc. Natl. Acad. Sci. U.S.A. 111, E3948-E3956. doi: 10.1073/pnas.1407927111

Meuer, J., Bartoschek, S., Koch, J., Künkel, A., and Hedderich, R. (1999). Purification and catalytic properties of Ech hydrogenase from Methanosarcina barkeri. Eur. J. Biochem. 265, 325-335. doi: 10.1046/j.1432-1327.1999.00738.x

Mitchell, P. (1975). The protonmotive Q cycle: a general formulation. FEBS Lett. 59, 137-139. doi: 10.1016/0014-5793(75)80359-0

Montag, D., and Schink, B. (2018). Comparison of formate and hydrogen as electron shuttles in terminal fermentations in an oligotrophic freshwater lake sediment. Appl. Environ. Microbiol. 84:AEM.01572-18. doi: 10.1128/AEM. 01572-18

Morris, B. E., Henneberger, R., Huber, H., and Moissl-Eichinger, C. (2013). Microbial syntrophy: interaction for the common good. FEMS Microbiol. Rev. 37, 384-406. doi: 10.1111/1574-6976.12019

Mukund, S., and Adams, M. W. (1995). Glyceraldehyde-3-phosphate ferredoxin oxidoreductase, a novel tungsten-containing enzyme with a potential glycolytic role in the hyperthermophilic archaeon Pyrococcus furiosus. J. Biol. Chem. 270, 8389-8392. doi: 10.1074/jbc.270.15.8389

Mulder, D. W., Boyd, E. S., Sarma, R., Lange, R. K., Endrizzi, J. A., Broderick, J. B., et al. (2010). Stepwise [FeFe]-hydrogenase $\mathrm{H}$-cluster assembly revealed in the structure of HydA(DeltaEFG). Nature 465, 248-251. doi: 10.1038/nature08993

Müller, V., Chowdhury, N. P., and Basen, M. (2018). Electron bifurcation: a longhidden energy-coupling mechanism. Annu. Rev. Microbiol. 72, 331-353. doi: 10.1146/annurev-micro-090816-093440

Nicolet, Y., Piras, C., Legrand, P., Hatchikian, C. E., and Fontecilla-Camps, J. C. (1999). Desulfovibrio desulfuricans iron hydrogenase: the structure shows unusual coordination to an active site Fe binuclear center. Structure 7, 13-23. doi: 10.1016/S0969-2126(99)80005-7

Nitschke, W., and Russell, M. J. (2012). Redox bifurcations: mechanisms and importance to life now, and at its origin: a widespread means of energy conversion in biology unfolds. Bioessays 34, 106-109. doi: 10.1002/bies. 201100134

Novelli, P. C., Lang, P. M., Masarie, K. A., Hurst, D. F., Myers, R., and Elkins, J. W. (1999). Molecular hydrogen in the troposphere: global distribution and budget. J. Geophys. Res. 104, 30427-30444. doi: 10.1029/1999JD900788

Peters, J. W., Beratan, D. N., Schut, G. J., and Adams, M. W. W. (2018). On the nature of organic and inorganic centers that bifurcate electrons, coupling exergonic and endergonic oxidation-reduction reactions. Chem. Commun. 54, 4091-4099. doi: 10.1039/c8cc01530a

Peters, J. W., Lanzilotta, W. N., Lemon, B. J., and Seefeldt, L. C. (1998). X-ray crystal structure of the $\mathrm{Fe}$-only hydrogenase $(\mathrm{Cpl})$ from Clostridium pasteurianum to 1.8 angstrom resolution. Science 282, 1853-1858. doi: 10.1126/science.282.5395. 1853

Pierik, A. J., Hulstein, M., Hagen, W. R., and Albracht, S. P. J. (1998). A lowspin iron with $\mathrm{CN}$ and $\mathrm{CO}$ as intrinsic ligands forms the core of the active site in [Fe]-hydrogenases. Eur. J. Biochem. 258, 572-578. doi: 10.1046/j.1432-1327. 1998.2580572.x

Pinske, C., and Sargent, F. (2016). Exploring the directionality of Escherichia coli formate hydrogenlyase: a membrane-bound enzyme capable of fixing carbon dioxide to organic acid. MicrobiologyOpen 5, 721-737. doi: 10.1002/mbo3.365

Pinske, C., and Sawers, R. G. (2016). Anaerobic formate and hydrogen metabolism. EcoSal Plus 7, doi: 10.1128/ecosalplus.ESP-0011-2016

Poehlein, A., Schmidt, S., Kaster, A.-K., Goenrich, M., Vollmers, J., Thürmer, A., et al. (2012). An ancient pathway combining carbon dioxide fixation with the generation and utilization of a sodium ion gradient for ATP synthesis. PLoS One 7:e33439. doi: 10.1371/journal.pone.0033439

Postgate, J. R., and Campbell, L. L. (1966). Classification of Desulfovibrio species, the nonsporulating sulfate-reducing bacteria. Bacteriol. Rev. 30, 732-738.

Preuster, P., Alekseev, A., and Wasserscheid, P. (2017a). Hydrogen storage technologies for future energy systems. Annu. Rev. Chem. Biomol. Eng. 8, 445-471. doi: 10.1146/annurev-chembioeng-060816-101334

Preuster, P., Papp, C., and Wasserscheid, P. (2017b). Liquid organic hydrogen carriers (LOHCs): toward a hydrogen-free hydrogen economy. Acc. Chem. Res. 50, 74-85. doi: 10.1021/acs.accounts.6b00474

Raaijmakers, H., Macieira, S., Dias, J. M., Teixeira, S., Bursakov, S., Huber, R., et al. (2002). Gene sequence and the 1.8 angstrom crystal structure of the tungsten-containing formate dehydrogenase from Desulfolvibrio gigas. Structure 10, 1261-1272. doi: 10.1016/S0969-2126(02)00826-2

Rittmann, S., and Herwig, C. (2012). A comprehensive and quantitative review of dark fermentative biohydrogen production. Microb. Cell Fact. 11:1. doi: 10.1186/1475-2859-11-115

Roger, M., Brown, F., Gabrielli, W., and Sargent, F. (2018). Efficient hydrogendependent carbon dioxide reduction by Escherichia coli. Curr. Biol. 28, 140-145. doi: 10.1016/j.cub.2017.11.050

Rossmann, R., Sawers, G., and Böck, A. (1991). Mechanism of regulation of the formate-hydrogenlyase pathway by oxygen, nitrate, and $\mathrm{pH}$ : definition of the formate regulon. Mol. Microbiol. 5, 2807-2814. doi: 10.1111/j.1365-2958.1991. tb01989.x

Rumpel, S., Siebel, J. F., Diallo, M., Fares, C., Reijerse, E. J., and Lubitz, W. (2015). Structural insight into the complex of ferredoxin and [FeFe] hydrogenase from Chlamydomonas reinhardtii. Chembiochem 16, 1663-1669. doi: 10.1002/cbic. 201500130

Sakaguchi, T., Arakaki, A., and Matsunaga, T. (2002). Desulfovibrio magneticus sp. nov., a novel sulfate-reducing bacterium that produces intracellular singledomain-sized magnetite particles. Int. J. Syst. Evol. Microbiol. 52, 215-221. doi: 10.1099/00207713-52-1-215

Sapra, R., Verhagen, M. F., and Adams, M. W. (2000). Purification and characterization of a membrane-bound hydrogenase from the hyperthermophilic archaeon Pyrococcus furiosus. J. Bacteriol. 182, 3423-3428. doi: 10.1128/JB.182.12.3423-3428.2000

Sauer, U., Canonaco, F., Heri, S., Perrenoud, A., and Fischer, E. (2004). The soluble and membrane-bound transhydrogenases UdhA and PntAB have divergent functions in NADPH metabolism of Escherichia coli. J. Biol. Chem. 279, 66136619. doi: $10.1074 /$ jbc.M311657200 
Sauter, M., Böhm, R., and Böck, A. (1992). Mutational analysis of the operon (hyc) determining hydrogenase 3 formation in Escherichia coli. Mol. Microbiol. 6, 1523-1532. doi: 10.1111/j.1365-2958.1992.tb00873.x

Sawers, G. (1994). The hydrogenases and formate dehydrogenases of Escherichia coli. Antonie Van Leeuwenhoek 66, 57-88. doi: 10.1007/BF00871633

Sawers, R. G. (2005). Formate and its role in hydrogen production in Escherichia coli. Biochem. Soc. Trans. 33, 42-46. doi: 10.1042/BST0330042

Sawers, R. G., Blokesch, M., and Böck, A. (2004). Anaerobic formate and hydrogen metabolism. EcoSal Plus 1, doi: 10.1128/ecosalplus.3.5.4

Schink, B. (1997). Energetics of syntrophic cooperation in methanogenic degradation. Microbiol. Mol. Biol. Rev. 61, 262-280.

Schink, B. (2002). Synergistic interactions in the microbial world. Antonie Van Leeuwenhoek 81, 257-261. doi: 10.1023/A:1020579004534

Schink, B., Montag, D., Keller, A., and Müller, N. (2017). Hydrogen or formate: alternative key players in methanogenic degradation. Environ. Microbiol. Rep. 9, 189-202. doi: 10.1111/1758-2229.12524

Schlapbach, L., and Zuttel, A. (2001). Hydrogen-storage materials for mobile applications. Nature 414, 353-358. doi: 10.1038/35104634

Schmidt, O., Drake, H. L., and Horn, M. A. (2010). Hitherto unknown [Fe$\mathrm{Fe}]$-hydrogenase gene diversity in anaerobes and anoxic enrichments from a moderately acidic fen. Appl. Environ. Microbiol. 76, 2027-2031. doi: 10.1128/ AEM.02895-09

Schroder, C., Selig, M., and Schonheit, P. (1994). Glucose fermentation to acetate, $\mathrm{CO}_{2}$ and $\mathrm{H}_{2}$ in the anaerobic hyperthermophilic eubacterium Thermotoga maritima - involvement of the Embden-Meyerhof pathway. Arch. Microbiol. 161, 460-470.

Schuchmann, K., and Müller, V. (2012). A bacterial electron bifurcating hydrogenase. J. Biol. Chem. 287, 31165-31171. doi: 10.1074/jbc.M112.395038

Schuchmann, K., and Müller, V. (2013). Direct and reversible hydrogenation of $\mathrm{CO}_{2}$ to formate by a bacterial carbon dioxide reductase. Science 342, 1382-1385. doi: $10.1126 /$ science. 1244758

Schuchmann, K., and Müller, V. (2014). Autotrophy at the thermodynamic limit of life: a model for energy conservation in acetogenic bacteria. Nat. Rev. Microbiol. 12, 809-821. doi: 10.1038/nrmicro3365

Schuchmann, K., and Müller, V. (2016). Energetics and application of heterotrophy in acetogenic bacteria. Appl. Environ. Microbiol. 82, 4056-4069. doi: 10.1128/ AEM.00882-16

Schuchmann, K., Vonck, J., and Müller, V. (2016). A bacterial hydrogen-dependent $\mathrm{CO}_{2}$ reductase forms filamentous structures. FEBS J. 283, 1311-1322. doi: 10. $1111 /$ febs. 13670

Schut, G. J., and Adams, M. W. (2009). The iron-hydrogenase of Thermotoga maritima utilizes ferredoxin and NADH synergistically: a new perspective on anaerobic hydrogen production. J. Bacteriol. 191, 4451-4457. doi: 10.1128/JB. 01582-08

Schwarz, F. M., Schuchmann, K., and Müller, V. (2018). Hydrogenation of $\mathrm{CO}_{2}$ at ambient pressure catalyzed by a highly active thermostable biocatalyst. Biotechnol. Biofuels 11:237. doi: 10.1186/s13068-018-1236-3

Seitz, H. J., Schink, B., Pfennig, N., and Conrad, R. (1990). Energetics of syntrophic ethanol oxidation in defined chemostat cocultures.2. Energy sharing in biomass production. Arch. Microbiol. 155, 89-93. doi: 10.1007/BF00291280

Selig, M., Xavier, K. B., Santos, H., and Schönheit, P. (1997). Comparative analysis of Embden-Meyerhof and Entner-Doudoroff glycolytic pathways in hyperthermophilic archaea and the bacterium thermotoga. Arch. Microbiol. 167, 217-232. doi: 10.1007/BF03356097

Service, R. F. (2004). The hydrogen backlash. Science 305, 958-961. doi: 10.1126/ science.305.5686.958

Shima, S., Pilak, O., Vogt, S., Schick, M., Stagni, M. S., Meyer-Klaucke, W., et al. (2008). The crystal structure of [Fe]-hydrogenase reveals the geometry of the active site. Science 321, 572-575. doi: 10.1126/science. 1158978

Shima, S., and Thauer, R. K. (2007). A third type of hydrogenase catalyzing $\mathrm{H}_{2}$ activation. Chem. Rec. 7, 37-46. doi: 10.1002/tcr.20111

Sieber, J. R., McInerney, M. J., and Gunsalus, R. P. (2012). Genomic insights into syntrophy: the paradigm for anaerobic metabolic cooperation. Ann. Rev. Microbiol. 66, 429-452. doi: 10.1146/annurev-micro-090110-102844

Soboh, B., Linder, D., and Hedderich, R. (2002). Purification and catalytic properties of a CO-oxidizing: $\mathrm{H}_{2}$-evolving enzyme complex from Carboxydothermus hydrogenoformans. Eur. J. Biochem. 269, 5712-5721. doi: 10.1046/j.1432-1033.2002.03282.x
Spruth, M., Reidlinger, J., and Muller, V. (1995). Sodium-ion dependence of inhibition of the $\mathrm{Na}^{+}$-translocating $\mathrm{F}_{1} \mathrm{~F}_{0}$-ATPase from Acetobacterium woodii probing the site(S) involved in ion-transport. BBA-Bioenerg. 1229, 96-102. doi: 10.1016/0005-2728(94)00192-8

Stadtman, T. C. (1996). Selenocysteine. Annu. Rev. Biochem. 65, 83-100. doi: 10.1146/annurev.bi.65.070196.000503

Stams, A. J., and Plugge, C. M. (2009). Electron transfer in syntrophic communities of anaerobic bacteria and archaea. Nat. Rev. Microbiol. 7, 568-577. doi: 10.1038/ nrmicro2166

Stephenson, M., and Stickland, L. H. (1931). Hydrogenase: a bacterial enzyme activating molecular hydrogen: the properties of the enzyme. Biochem. J. 25, 205-214. doi: 10.1042/bj0250205

Stephenson, M., and Stickland, L. H. (1932). Hydrogenlyases: bacterial enzymes liberating molecular hydrogen. Biochem. J. 26, 712-724. doi: 10.1042/bj0260712

Stock, T., and Rother, M. (2009). Selenoproteins in archaea and Gram-positive bacteria. Biochim. Biophys. Acta 1790, 1520-1532. doi: 10.1016/j.bbagen.2009. 03.022

Thauer, R. K., Jungermann, K., and Decker, K. (1977). Energy conservation in chemotrophic anaerobic bacteria. Bacteriol. Rev. 41, 100-180.

Thauer, R. K., Kaster, A. K., Goenrich, M., Schick, M., Hiromoto, T., and Shima, S. (2010). Hydrogenases from methanogenic archaea, nickel, a novel cofactor, and $\mathrm{H}_{2}$ storage. Annu. Rev. Biochem. 79, 507-536. doi: 10.1146/annurev.biochem. 030508.152103

Thauer, R. K., Kaster, A. K., Seedorf, H., Buckel, W., and Hedderich, R. (2008). Methanogenic archaea: ecologically relevant differences in energy conservation. Nat. Rev. Microbiol. 6, 579-591. doi: 10.1038/nrmicro1931

Thiele, J. H., and Zeikus, J. G. (1988). Control of interspecies electron flow during anaerobic digestion: significance of formate transfer versus hydrogen transfer during syntrophic methanogenesis in flocs. Appl. Environ. Microbiol. 54, 20-29.

Trchounian, A., Bagramyan, K., and Poladian, A. (1997). Formate hydrogenlyase is needed for proton-potassium exchange through the $\mathrm{F}_{0} \mathrm{~F}_{1}$ ATPase and the TrkA system in anaerobically grown and glycolysing Escherichia coli. Curr. Microbiol. 35, 201-206. doi: 10.1007/s0028499 00239

Trchounian, A., and Sawers, R. G. (2014). Novel insights into the bioenergetics of mixed-acid fermentation: can hydrogen and proton cycles combine to help maintain a proton motive force? IUBMB Life 66, 1-7. doi: 10.1002/iub.1236

Trchounian, A. A., Bagramyan, K. A., Vassilian, A. V., and Poladian, A. A. (2000). Relationship between formate hydrogen lyase and proton-potassium pump under heterolactic fermentation in Escherichia coli: functional multienzyme associations in the cell membrane. Membr. Cell Biol. 13, 511-526.

Trchounian, K., Pinske, C., Sawers, R. G., and Trchounian, A. (2011). Dependence on the $\mathrm{F}_{0} \mathrm{~F}_{1}$-ATP synthase for the activities of the hydrogen-oxidizing hydrogenases 1 and 2 during glucose and glycerol fermentation at high and low $\mathrm{pH}$ in Escherichia coli. J. Bioenerg. Biomembr. 43, 645-650. doi: 10.1007/s10863-0119397-9

Trchounian, K., and Trchounian, A. (2014). Different role of focA and focB encoding formate channels for hydrogen production by Escherichia coli during glucose or glycerol fermentation. Int. J. Hydrogen Energy 39, 20987-20991. doi: 10.1016/j.ijhydene.2014.10.074

Tremel, A., Wasserscheid, P., Baldauf, M., and Hammer, T. (2015). Technoeconomic analysis for the synthesis of liquid and gaseous fuels based on hydrogen production via electrolysis. Int. J. Hydrogen Energy 40, 11457-11464. doi: 10.1016/j.ijhydene.2015.01.097

Ursua, A., Gandia, L. M., and Sanchis, P. (2012). Hydrogen production from water electrolysis: current status and future trends. Proc. IEEE 100, 410-426. doi: 10.1109/JPROC.2011.2156750

van Niel, E. W. (2016). Biological processes for hydrogen production. $A d v$. Biochem. Eng. Biotechnol. 156, 155-193. doi: 10.1007/10_2016_11

Verhagen, M. F. J. M., O'Rourke, T., and Adams, M. W. W. (1999). The hyperthermophilic bacterium, Thermotoga maritima, contains an unusually complex iron-hydrogenase: amino acid sequence analyses versus biochemical characterization. Biochim. Biophys. Acta 1412, 212-229. doi: 10.1016/S00052728(99)00062-6

Vignais, P. M., and Billoud, B. (2007). Occurrence, classification, and biological function of hydrogenases: an overview. Chem. Rev. 107, 4206-4272. doi: 10. $1021 / \mathrm{cr} 050196 \mathrm{r}$ 
Vignais, P. M., Billoud, B., and Meyer, J. (2001). Classification and phylogeny of hydrogenases. FEMS Microbiol. Rev. 25, 455-501. doi: 10.1111/j.1574-6976. 2001.tb00587.x

Vignais, P. M., and Colbeau, A. (2004). Molecular biology of microbial hydrogenases. Curr. Issues Mol. Biol. 6, 159-188.

Volbeda, A., Charon, M. H., Piras, C., Hatchikian, E. C., Frey, M., and FontecillaCamps, J. C. (1995). Crystal structure of the nickel-iron hydrogenase from Desulfovibrio gigas. Nature 373, 580-587. doi: 10.1038/373580a0

Wagner, T., Koch, J., Ermler, U., and Shima, S. (2017). Methanogenic heterodisulfide reductase (HdrABC-MvhAGD) uses two noncubane [4Fe-4S] clusters for reduction. Science 357, 699-703. doi: 10.1126/science.aan0425

Wang, S., Huang, H., Kahnt, J., Mueller, A. P., Köpke, M., and Thauer, R. K. (2013a). NADP-specific electron-bifurcating [FeFe]-hydrogenase in a functional complex with formate dehydrogenase in Clostridium autoethanogenum grown on CO. J. Bacteriol. 195, 4373-4386. doi: 10.1128/JB.00678-13

Wang, S., Huang, H., Kahnt, J., and Thauer, R. K. (2013b). A reversible electronbifurcating ferredoxin- and NAD-dependent [FeFe]-hydrogenase (HydABC) in Moorella thermoacetica. J. Bacteriol. 195, 1267-1275. doi: 10.1128/JB.02158-12

Wang, W. H., Himeda, Y., Muckerman, J. T., Manbeck, G. F., and Fujita, E. (2015). $\mathrm{CO}_{2}$ hydrogenation to formate and methanol as an alternative to photo- and electrochemical $\mathrm{CO}_{2}$ reduction. Chem. Rev. 115, 12936-12973. doi: 10.1021/ acs.chemrev.5b00197

Wang, Y., Huang, Y., Wang, J., Cheng, C., Huang, W., Lu, P., et al. (2009). Structure of the formate transporter FocA reveals a pentameric aquaporin-like channel. Nature 462, 467-472. doi: 10.1038/nature08610

Weghoff, M. C., Bertsch, J., and Müller, V. (2015). A novel mode of lactate metabolism in strictly anaerobic bacteria. Environ. Microbiol. 17, 670-677. doi: 10.1111/1462-2920.12493

Welte, C., Kallnik, V., Grapp, M., Bender, G., Ragsdale, S., and Deppenmeier, U. (2010a). Function of Ech hydrogenase in ferredoxin-dependent, membranebound electron transport in Methanosarcina mazei. J. Bacteriol. 192, 674-678. doi: 10.1128/JB.01307-09

Welte, C., Krätzer, C., and Deppenmeier, U. (2010b). Involvement of Ech hydrogenase in energy conservation of Methanosarcina mazei. FEBS J. 277, 3396-3403. doi: 10.1111/j.1742-4658.2010.07744.x

Wood, H. G. (1991). Life with $\mathrm{CO}$ or $\mathrm{CO}_{2}$ and $\mathrm{H}_{2}$ as a source of carbon and energy. FASEB J. 5, 156-163. doi: 10.1096/fasebj.5.2.1900793
Wood, H. G., and Ljungdahl, L. G. (1991). “Autotrophic character of the acetogenic bacteria," in Variations in Autotrophic Life, eds J. M. Shively and L. L. Barton (San Diego: Academic press), 201-250.

Wrba, A., Jaenicke, R., Huber, R., and Stetter, K. O. (1990). Lactate dehydrogenase from the extreme thermophile Thermotoga maritima. Eur. J. Biochem. 188, 195-201. doi: 10.1111/j.1432-1033.1990.tb15388.x

Yamamoto, I., Saiki, T., Liu, S. M., and Ljungdahl, L. G. (1983). Purification and properties of NADP-dependent formate dehydrogenase from Clostridium thermoaceticum, a tungsten-selenium-iron protein. J. Biol. Chem. 258, 18261832.

Yishai, O., Lindner, S. N., Gonzalez de la Cruz, J., Tenenboim, H., and BarEven, A. (2016). The formate bio-economy. Curr. Opin. Chem. Biol. 35, 1-9. doi: 10.1016/j.cbpa.2016.07.005

Zheng, Y., Kahnt, J., Kwon, I. H., Mackie, R. I., and Thauer, R. K. (2014). Hydrogen formation and its regulation in Ruminococcus albus: involvement of an electron-bifurcating [FeFe]-hydrogenase, of a non-electron-bifurcating [FeFe]-hydrogenase, and of a putative hydrogen-sensing [FeFe]-hydrogenase. J. Bacteriol. 196, 3840-3852. doi: 10.1128/JB.02070-14

Zindel, U., Freudenberg, W., Rieth, M., Andreesen, J. R., Schnell, J., and Widdel, F. (1988). Eubacterium acidaminophilum sp. nov., a versatile amino acid-degrading anaerobe producing or utilizing $\mathrm{H}_{2}$ or formate. Description and enzymatic studies. Arch. Microbiol. 150, 254-266. doi: 10.1007/BF00407789

Zinoni, F., Birkmann, A., Stadtman, T. C., and Böck, A. (1986). Nucleotide sequence and expression of the selenocysteine-containing polypeptide of formate dehydrogenase (formate-hydrogen-lyase-linked) from Escherichia coli. Proc. Natl. Acad. Sci. U.S.A. 83, 4650-4654. doi: 10.1073/pnas.83.13.4650

Conflict of Interest Statement: The authors declare that the research was conducted in the absence of any commercial or financial relationships that could be construed as a potential conflict of interest.

Copyright (C) 2018 Schuchmann, Chowdhury and Müller. This is an open-access article distributed under the terms of the Creative Commons Attribution License (CC BY). The use, distribution or reproduction in other forums is permitted, provided the original author(s) and the copyright owner(s) are credited and that the original publication in this journal is cited, in accordance with accepted academic practice. No use, distribution or reproduction is permitted which does not comply with these terms. 